\title{
El campesinado y la distribución de la tierra en la Atenas del siglo IV a.C.
}

\author{
Julián GALLEGO \\ Universidad de Buenos Aires-CONICET/PEFSCEA \\ julianalejandrogallego@hotmail.com
}

Recibido: 31 de octubre de 2015

Aceptado: 8 de febrero de 2016

\section{RESUMEN}

El artículo propone un estudio de la economía rural ateniense en el siglo IV a.C., asumiendo que las devastaciones durante la Guerra del Peloponeso no tuvieron efectos permanentes sobre la agricultura ática, que tuvo una rápida recuperación. En este marco, se examina la situación del campesinado en relación con los demás sectores socioeconómicos que pueden distinguirse dentro de la población de ciudadanos residentes en el Ática. Para sopesar el posible declive de la importancia del campesinado, que una visión ya tradicional asocia con las consecuencias inmediatas de la guerra, se formula un análisis cuantitativo de la distribución de la tierra. Se parte para ello de los datos sobre población y riqueza de los censos de Antípatro y Demetrio de Falero y se usa una equivalencia que se desprende de las rationes centesimarum. Esta información es compaginada con otra serie de datos en la que se incluye una inferencia sobre el reparto de las cargas de la eisphorá entre los tributarios. Los resultados obtenidos se ponderan mediante un cálculo del coeficiente de Gini y enfoques comparativos. La conclusión es que en la Atenas del siglo IV a.C. la distribución de la tierra era razonablemente equitativa, cotejada con otros casos, y que el campesinado continuó teniendo un rol protagónico.

Palabras clave: Campesinado. Propiedad de la tierra. Riqueza. Población. Ciudadanía. Igualdad.

\section{Peasantry and the Distribution of Land in Fourth-Century B.C. Athens}

\begin{abstract}
The article proposes a study of the Athenian rural economy in the fourth century B.C., assuming that devastations during the Peloponnesian War did not have permanent effects on Attic agriculture, which recovered quickly. In this context, the situation of the peasantry is examined in relation to the other socio-economic sectors of the citizen population living in Attica. A quantitative analysis of the distribution of land is formulated in order to weigh the possible decline of the importance of the peasantry (a traditional view that associates this with the immediate impacts of war). For this, information about population and wealth from the censuses of Antipater and of Demetrius of Phaleron is considered and a relative proportion emerging from the rationes centesimarum is used. The figures obtained are pulled together with other data series, including an inference about the burden sharing among taxpayers of the eisphora system. The results are weighted by calculating the Gini coefficient and by comparative approaches. The conclusion is that the distribution of land in fourth-century Athens was reasonably egalitarian, compared to other cases, and that the peasantry continued to have a significant role.
\end{abstract}

Keywords: Peasantry. Landownership. Wealth. Population. Citizenship. Equality.

Sumario: 1. Introducción. 2. Diferenciación social y distribución de la tierra. 3. Población y riqueza según los censos de Antípatro y Demetrio. 4. Un posible patrón entre valor monetario y unidad de superficie. 5. Calculando la distribución de la tierra. 6. La riqueza del campesinado ático. 7. Conclusión. 


\section{Introducción}

En las últimas décadas, nuestra visión de los labradores áticos durante el siglo IV a.C. ${ }^{1}$ se ha transformado en la misma medida en que han cobrado fuerza interpretaciones coincidentes que descartan una crisis o un declive irreversible de la agricultura campesina en la Atenas posterior a la Guerra del Peloponeso. Por el contrario, diversos indicadores parecen dar cuenta de un auge renovado que más temprano que tarde dejaría atrás las incidencias inmediatas de las contiendas militares sobre la labranza, ${ }^{2}$ lo cual vendría a dar sustento a quienes sostienen la continuada importancia de la granja familiar como unidad productiva a través de la cual se organizaba una parte significativa de la economía rural ateniense. ${ }^{3}$ Esto permite también una revisión del lugar común divulgado por Michel Austin y Pierre Vidal-Naquet concerniente al abandono del ideal del campesino-ciudadano a lo largo del siglo IV. ${ }^{4}$ En este artículo vamos a argumentar a favor de las posturas que señalan tanto el auge de la agricultura como el renovado protagonismo del campesinado ático, echando mano de un conjunto de elementos cuantitativos que si bien no configuran un cuadro estadístico pueden servir de orientación respecto de las condiciones demográficas y agrarias de la Atenas del siglo IV.

La cuantificación de los datos para el mundo antiguo es siempre difícil y debatible debido a la falta de estadísticas producidas por las propias sociedades y a la poca confianza que generan muchos de los números que nos llegan a través de las fuentes literarias. No obstante, muchas veces estos datos son los únicos a nuestra disposición para poder conjeturar un modelo razonable en términos socioeconómicos cuantitativos. Los estudios arqueológicos y epigráficos han producido evidencias más fiables referidas a la cuantificación de la economía ateniense pero solo para algunos aspectos parciales. En un artículo sobre la distribución de la riqueza en Atenas que se adentra en el núcleo del problema a estudiar, Geoffrey Kron señala la escasez de análisis cuantitativos acerca del problema planteado en el marco de la Grecia antigua a causa precisamente de las dificultades indicadas. El esfuerzo de Kron por salir de este atolladero es muy valioso y brinda una importante ayuda para nuestros fines aquí. ${ }^{5}$ Por nuestra parte, en este estudio nos valdremos de una serie de trabajos, referidos a población, estructura y clases sociales, producción agraria, tamaño de los lotes, precios de ventas o arrendamientos de tierras, etc., que permite en su conjunto establecer algunos indicadores cuantitativos de un modo razonable para poder delimitar el pro-

1 Salvo que se indique lo contrario, en adelante todas las fechas son a.C.

2 Ver e.g. Hanson 1998², 131-173; Osborne 1987, 137-164; Foxhall 1993. Cf. Thorne 2001.

3 Cf. Lewis 1973, 194-199; ANDreyev 1974, 27-29; PeČIrka 1976, 13-14; DesCAT 1987, 241-246; FrenCH 1991, 24-30; MORRIS 2000, 138-144.

4 Austin - Vidal-Naquet 1972, 175-176, 397-400. Cf. Gallego - Valdés Guía 2014, 213-238.

5 KRON 2011. Varios estudiosos han planteado estimaciones cuantitativas de la riqueza: RUSCHENBUSCH 1985; Foxhall 1992; Osborne 2010, 92-94, 112-116, 127-138. Morris 2000, 140-142, retoma los cálculos de los dos últimos autores y deduce el coeficiente de Gini; Bresson 2007, 150-151, se basa en los datos de Burford 1977/78, 171, y el índice de Gini elaborado por Morris; OBer 2010, 257-259, revisa varios de los trabajos publicados y sintetiza los resultados alcanzados por los mismos; cf. vAN WEES 2011, 112-113. 
blema de la distribución de la tierra en la Atenas del siglo IV y el rol del campesinado en este contexto.

\section{Diferenciación social y distribución de la tierra}

En un análisis previo, hemos planteado la idea de que los zeugîtai de las reformas solonianas constituían un conjunto cuyos integrantes se definían por la posesión de una yunta de bueyes, condición ligada a la propiedad de un lote de alrededor de 5 ha, ${ }^{6}$ e integraban el grueso de la falange hoplítica, aun cuando no se identificasen plenamente con los hoplitas. ${ }^{7}$ Delineamos este argumento en debate con Hans van Wees que considera a los zeugîtai como parte de la clase ociosa, puesto que cada uno debió de haber poseído 8 ha o más, según sus propias estimaciones sobre la superficie necesaria para llegar al mínimo de 200 "medidas ( $\mu \varepsilon ́ \tau \rho \alpha)$ de áridos y líquidos en conjunto" exigidas para incluir a un propietario dentro de la clase de los zeugitai. ${ }^{8}$ Nuestra propuesta parte de la hipótesis de que, en realidad, los zeugîtai poseedores de 8 ha o más constituyeron solo un sector minoritario de la clase censitaria de los zeugîtai, definida en tiempos de Solón fundamentalmente a partir de la posesión de una yunta de bueyes. En efecto, en la coyuntura de la Guerra del Peloponeso, los zengîtai poseedores de 8 ha o más, es decir, los más ricos, habrían comenzado a distinguirse como un sector específico, cuando en 428 se establecieron ciertas delimitaciones para realizar la recaudación entre los atenienses más ricos de la primera eisphorá de la que se tiene registro (tributo sobre el patrimonio, recolectado con fines bélicos). Sobre la base de esta modificación práctica se habría producido una posterior adaptación de las clases censitarias, tal vez en 403 al entrar en vigencia la revisión de las llamadas "leyes de Solón" tras la restauración de la democracia luego del golpe oligárquico de los Treinta tiranos, hasta que en 378 se produjo una completa reorganización de la eisphorá sobre nuevos criterios.

La perspectiva de van Wees se encuadra en un debate más amplio sobre cuán igualitaria fue la sociedad ateniense y se liga directamente al enfoque de Lin Foxhall que plantea una fuerte diferenciación socioeconómica entre ciudadanos ricos y pobres. Precisamente, Foxhall había elaborado un modelo para el Ática del siglo IV según el cual "el patrón de distribución de la tierra... sugiere fuertemente una realidad de desigualdad que contrasta claramente con el ideal de la democracia del campesinociudadano". ${ }^{9}$ Para van Wees y Foxhall, Atenas sería una ciudad cuya riqueza principal, la tierra, se hallaba en su mayor parte controlada por una clase ociosa que se beneficiaba de la explotación de una fuerza de trabajo dependiente. Al mismo tiempo,

6 Uso de bueyes en lotes de 5 ha, Halstead 1987, 84; BuRFord 1993, 67.

7 Gallego - Valdés Guía 2014, 151-186.

8 Arist., Ath., 7.4. van WeEs 2001 concede menor peso a la rotación bienal; según sus estimaciones sólo se dejaría en barbecho 1/5 del total de las tierras de granos; así, la granja mínima de un zeugites sería de 8,7 ha. VAN WeES 2006 toma como pauta la rotación bienal con barbecho; la obtención de 200 medidas implica 8 ha, que se duplican llegando a 16 ha para el zeugites de menor riqueza (la ecuación cambia si se siguen los cálculos de STroud 1998, 55, y Moreno 2007, 325-326, respecto del médimnos y el metretés).

9 Foxhall 1992, 159; cf. EAD. 1997 (donde la autora analiza las clases solonianas); EAD. 2002. 
la presencia de un sector de campesinos autónomos, si bien importante, quedaría subsumida en la polarización entre ricos y pobres, ya que no habría una "clase media" de labradores sino una marcada división entre la élite y el resto de la ciudadanía. Ahora bien, aunque el modo de definir a los zeugittai pudo haber variado conforme a las mutaciones que hemos indicado en nuestra crítica a van Wees, el problema que subsiste es el de ponderar el peso relativo de los labradores con respecto al total de atenienses varones adultos y según las pautas de distribución de la tierra, tanto de los medianos que poseían una yunta como de los pequeños capaces de reproducirse autárquicamente a partir del trabajo en sus granjas.

En este marco, Foxhall ha realizado un interesante ejercicio para cuantificar la distribución de la tierra apta para algún tipo de producción entre los diferentes sectores de la población ciudadana, asunto que constituirá el eje de nuestro trabajo (Fig. 1). ${ }^{10}$ Asumiendo una población total de 30.000 varones adultos, ${ }^{11}$ Foxhall conjetura la existencia de 22.000 hogares, ${ }^{12}$ de los cuales cerca de 2.000 corresponderían a los atenienses más ricos, ${ }^{13}$ mientras que unos 5.000 hogares carecerían completamente de tierras, si se acepta la veracidad de la propuesta de decreto presentada por un tal Formisio, finalmente no aprobada. ${ }^{14}$

Figura 1. Distribución de la propiedad de la tierra según Foxhall.

\begin{tabular}{|c|c|c|c|c|c|c|c|}
\hline \multicolumn{2}{|c|}{ Hogares } & \multirow{2}{*}{$\begin{array}{c}\begin{array}{c}\text { Tamaño } \\
\text { de lotes }\end{array} \\
20-50+\text { ha }\end{array}$} & \multirow{3}{*}{$\begin{array}{c}\begin{array}{c}\text { Lote } \\
\text { promedio }\end{array} \\
20 \text { ha }(220 \\
\text { plethra })\end{array}$} & \multirow{3}{*}{$\begin{array}{c}\begin{array}{c}\text { Porcentaje } \\
\text { de hogares }\end{array} \\
9 \%\end{array}$} & \multirow{3}{*}{$\begin{array}{c}\text { Porcentaje } \\
\text { de tierras }\end{array}$} & \multirow{3}{*}{$\begin{array}{c}\begin{array}{c}\text { Área para } \\
\text { cada grupo }\end{array} \\
350 \mathrm{~km}^{2}\end{array}$} & \multirow{3}{*}{$\begin{array}{c}\begin{array}{c}\text { Nuevo lote } \\
\text { promedio }\end{array} \\
17,5 \text { ha o } \\
194 \text { plethra }\end{array}$} \\
\hline \multirow[t]{2}{*}{2.000} & 1.000 & & & & & & \\
\hline & 1.000 & $10-20$ ha & & & & & \\
\hline \multirow[t]{3}{*}{15.000} & 10.000 & $5,5-10$ ha & \multirow{2}{*}{$\begin{array}{c}5,5 \text { ha }(60 \\
\text { plethra })\end{array}$} & \multirow[t]{2}{*}{$68 \%$} & \multirow[t]{2}{*}{$55 \%$} & \multirow[t]{2}{*}{$550 \mathrm{~km}^{2}$} & \multirow{2}{*}{$\begin{array}{c}3,6 \text { ha o } \\
40 \text { plethra }\end{array}$} \\
\hline & 5.000 & $<5,5$ ha & & & & & \\
\hline & 5.000 & 0 & 0 & $23 \%$ & 0 & 0 & 0 \\
\hline \multicolumn{2}{|c|}{22.000} & ----- & ----- & $100 \%$ & $90 \%{ }^{15}$ & $900 \mathrm{~km}^{2}$ & ----- \\
\hline
\end{tabular}

10 Foxhall 1992, passim; cf. 158, Fig. 1 y 2.

11 Una estimación en la que coinciden muchos historiadores actualmente: cf. HANSEN 1985; ID. $1988 ;$ ID. 1991, 86-94; Williams 1983; SAllares 1991, 51-60; RosivaCH 1993; Oliver 2007, 79-83.

12 Foxhall 1992, 156, siguiendo a Jameson 1977/78, 125; cf. Gomme 1933, 26.

13 La clase litúrgica que analiza Davies 1971; Foxhall 1992, 157, estima una cantidad mayor de atenienses ricos. Según OsBorne 2010, 92-94, 130-135, había unos 2.000 hogares ricos con alrededor de 3.000 ciudadanos.

14 Formisio habría propuesto restringir la ciudadanía plena solo a los propietarios, excluyendo a unos 5.000 atenienses; D.H., Lys., 32; FuKs 1953, 41-47; MARKLe 1990, 158-159. No se sabe si se exigía una propiedad mínima. Gomme 1933, 26-27, descartaba el documento pero sus cálculos se acercan a lo consignado aquí. Se debe sopesar la mortalidad causada por la guerra y cómo pudo afectar de modo diferente a hoplitas y thêtes; cf. STRAuss 1986, 70-86, 179-182; HANSEN 1988, 14-28; HANSON 1995, 306-312, 365-390; BRULÉ 1999.

15 Sobre $1.000 \mathrm{~km}^{2}$ de tierra útil, el 10\% se considera tierra pública, arrendada por los más ricos según FoXHALl 1992, 157. 


\section{Población y riqueza según los censos de Antípatro y Demetrio}

Es un punto fuera de discusión que la principal forma de riqueza en la Grecia antigua era la tierra. Aun cuando las evidencias disponibles han permitido realizar importantes análisis de actividades comerciales, prácticas bancarias, inversiones de riesgo, etc. ${ }^{16}$ este punto resulta incontrovertible también para la Atenas del siglo IV. Sin negar la posesión de riqueza bajo otras formas distintas de la propiedad de la tierra (bienes muebles, inversiones bancarias o comerciales, dinero, etc.), lo argumentado nos lleva a centrar nuestra atención en este tipo de riqueza. Por ende, un modo de estimar la riqueza sería acceder a algún tipo de registro de las posesiones agrarias en el Ática. Lamentablemente no tenemos nada parecido, aunque existe entre los especialistas una discusión planteada en torno a este problema que parece inclinarse últimamente, como ya veremos, hacia la idea de que hubo registros de propiedades en los demos a cargo de los demarcos, contando para ello con la colaboración de los demotas que como vecinos solían conocer las situaciones patrimoniales de sus propias localidades.

Para avanzar con nuestra reconsideración partiremos de tres pasajes documentales de Diodoro Sículo, Plutarco y Ctesicles, respectivamente, que refieren cifras de población y requisitos económicos en el marco de las reformas constitucionales de Antípatro y Demetrio de Falero, a finales del siglo IV, cuando Atenas había quedado subordinada al poder macedónico. Diodoro señala que, en 322/21, Antípatro impuso

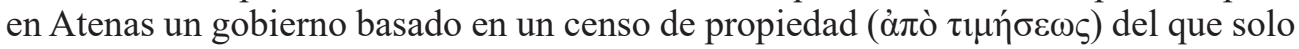
podían participar los atenienses que poseyeran un mínimo de 2.000 dracmas. ${ }^{17} \mathrm{Como}$

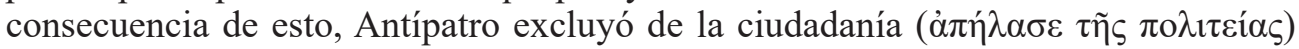
a los que poseían menos que esa riqueza, ofreciéndoles a los que quisieran de entre

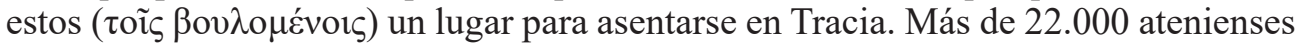
debieron entonces dejar Atenas, mientras que unos 9.000 habrían quedado al frente de la ciudad. Sin embargo, como ha subrayado Elisabetta Poddighe, es interesante señalar que tras aludir a ambos grupos Diodoro cierra el pasaje diciendo que se les permitió a todos conservar sus posesiones sin sufrir confiscación alguna ( $\pi \alpha ́ v \tau \varepsilon \varsigma \delta \grave{\varepsilon}$

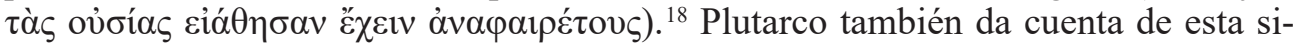
tuación pero afirmando que fueron un poco más de 12.000 los atenienses que se vie-

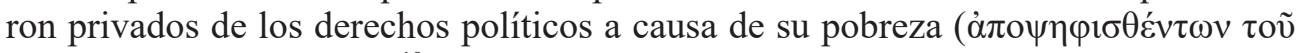

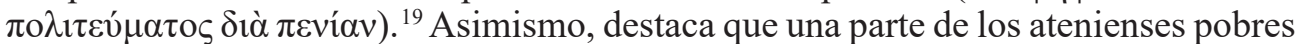
se quedó en el Ática pero a costa de sufrir una situación miserable, en tanto que otra parte emigró a Tracia para formar una ciudad y obtener tierras allí, pero asemejándose por su condición a prisioneros de guerra.

Se ha querido enmendar el texto de Diodoro a partir del de Plutarco, suponiendo que fueron 12.000 y no 22.000 los atenienses privados de los plenos derechos de ciudadanía por no poder alcanzar el censo requerido. De modo que, con este ajuste, el total de ciudadanos con plenos derechos junto a los excluidos de la ciudadanía coin-

16 Ver e.g. Cohen 1992; SHIPTON 2000; ReEd 2003.

17 D.S., 18.18.4-5.

18 Poddighe 2002, 93, 132-134, 137.

19 Plu., Phoc., 28.4. 
cidiría aproximadamente con el número de 21.000 ciudadanos que transmite un texto de Ctesicles al consignar un censo de población que se habría llevado a cabo durante la regencia de Demetrio de Falero, ${ }^{20}$ entre 317 y 307 (probablemente, el censo se hiciera en 317/16). ${ }^{21}$ Este dato sería en parte compatible con el relato de Diodoro acerca del acuerdo alcanzado, cuando se realizaron las negociaciones de paz con Casandro, para que el gobierno se organizara sobre la base de cualificaciones de propiedad ( $\dot{\alpha} \pi$ ò $\tau \mu \mu \eta ́ \sigma \varepsilon \omega v)$ hasta un mínimo de 10 minas, es decir, 1.000 dracmas. ${ }^{22}$

El problema recurrente es cómo interpretar estos datos que ponen en relación el tamaño de la población ateniense masculina adulta con la riqueza poseída, que si bien se expresa en valores monetarios implica, no obstante, unas propiedades agrarias que tanto en superficie como en rendimiento debieron permitir alcanzar los censos establecidos. ${ }^{23}$ Arnold Gomme pensaba que la cantidad de ciudadanos con 2.000 dracmas o más del censo de Antípatro era sorprendentemente baja, puesto que creía que esta cifra se relacionaba con un ingreso de 200 dracmas anuales, o 200 médimnoi en época de Solón, a razón de una dracma por médimnos. ${ }^{24}$ Sin embargo, considerando que el precio del médimnos de trigo en el siglo IV podía rondar las 6 dracmas y el de cebada alrededor de 3 dracmas, y si además se suman olivos y vides, no resultaría creíble que en 322 solo 9.000 lograran obtener 200 dracmas al año. ${ }^{25}$ Arnold Jones pensaba que Antípatro habría llegado a la cifra de 2.000 dracmas a partir de multiplicar por 10 el censo soloniano de 200 métra requerido para ser un zeugítes, que coincidiría con el hoplita, y brindaba una explicación de cómo se traducirían en 200 dracmas, aportando también la referencia de la renta de 2 minas percibida por cada cleruco ateniense a partir de los 2.700 lotes repartidos en Lesbos hacia 427 tras reprimir la revuelta de los mitileneos. ${ }^{26}$ Pero el autor aceptaba la idea de que hacia 322 solo habría 9.000 hoplitas - cantidad que a su entender sería constante a lo largo del siglo IV, e incluso

20 Ctesicles, FGrHist $245 \mathrm{~F} 1$, apud Ath., 6.103 (272 C).

21 Cf. Hansen 1985, 28-36; SeKunda 1992, 319-320; Lape 2004, 43-44. El número de ciudadanos de Plutarco procedería del censo de Demetrio de Falero, tal vez su fuente principal; por eso decía que fueron 12.000 los ciudadanos excluidos en 322. La fuente de Diodoro parece haber sido Jerónimo de Cardia. VAN WeEs 2011, 108-109 (cf. 96-101, 107-110), analiza los números de los censos y sus implicaciones económicas y demográficas.

22 D.S., 18.74.3. Cf. van WeEs 2011, 96-97, sobre la traducción de este pasaje.

23 Gomme 1933, 17-18; Jones 1957, 7-9, 28-29, 79, 142, n. 50; Brun 1983, 19; Hansen 1985, 28. Para más referencias véase Poddighe 2002, 109-140. Cf. Oliver 2007, 80-81; O'Sullivan 2009, 27 y n. 47, 115116 y n. 27; BaYliss 2011, 71; vaN WeEs 2011, 98.

24 Gomme 1933, 18 y n. 2.

25 GAUTHIER 1966, 76: un mínimo vital; Brunt 1993, 134-135: una suma modesta. IG II $^{2} 1672: 6$ dracmas por médimnos de trigo y 3 dracmas por médimnos de cebada; Pritchett 1956, 186, 197; MarkLe 1985, 293294; Stroud 1998, 32-33, 63; Rosivach 2000, 53-55; Engen 2010, 81-83, 87-88. Fluctuación en el precio de los granos: Stroud 1998, 74, n. 175; HARRIS 2002, 75-79; BRESSON 2000, 183-210; AMEMIYA 2007, 68-69.

26 JONES 1957, 7-9, 29-31, 76-81, 142, n. 50, citando a Lys., 7.39, señala que en el siglo IV las clases solonianas se basaban en la propiedad, no en el ingreso. Las 200 medidas se traducen a dracmas a partir de Plu., Sol., 23.3: una dracma por médimnos o por oveja, según el cómputo para los sacrificios. JAMESON $1977 / 78,125$, n. 13, acepta el cálculo por el cual se llega a las 2.000 dracmas. Los 2.700 lotes repartidos entre los clerucos atenienses siguieron siendo trabajados por los lesbios, obligados a pagar una renta de 2 minas al año; cf. Th., 3.50.2. Esta suma sería análoga a los ingresos requeridos para formar parte del estatus hoplita: Gauthier 1966; Andreyev 1974, 14; Hornblower 1991, 440-441; Brunt 1993, 125-129; Moreno 2007, 95; ID. 2009, 214. 
con antecedentes en el V-, ${ }^{27}$ definiendo a quienes se hallaban en el límite de las 2.000 dracmas como "hombres muy pobres".

En su análisis del censo de Antípatro, Elisabetta Poddighe señala que no pudo haber estado basado únicamente en la propiedad de la tierra, y que debió incluir también bienes muebles (al menos algunos ítems). A partir de esto, deduce que el nivel de riqueza mínimo exigido no era alto, por lo que los excluidos debieron de ser atenienses extremadamente pobres. ${ }^{28} \mathrm{La}$ autora pretende así desestimar la perspectiva mayoritaria que ha asociado a los 9.000 del censo de 322/21 con la base económica mínima requerida para formar parte de la clase de los zeugittai solonianos, relacionando a éstos explícita o implícitamente con el rango hoplítico, aunque incluyendo obviamente a las dos clases solonianas superiores. En contraste con esta visión, el reciente estudio de Andrew Bayliss estima que el nivel censitario mínimo exigido resultaba muy elevado y que su finalidad no habría sido establecer una "línea de pobreza", que habría llevado a la exclusión de quienes no alcanzaban el mínimo establecido, sino todo lo contrario, ya que "parece más probable que 2.000 dracmas representaran lo que los atenienses más ricos consideraban que era la línea que separaba a los «más excelentes» (i.e. ellos mismos) de los «carentes de valor» (i.e. todos los demás)". ${ }^{29}$

Desde nuestro punto de vista, ambas posturas adolecen del mismo problema, manifestado con un sentido inverso en cada caso. En efecto, si 9.000 es la cantidad de ciudadanos que excluye a los extremadamente pobres, según se sigue de la propuesta de Poddighe, entonces la Atenas del siglo IV habría sido el escenario de una gran concentración de la riqueza, aun cuando los atenienses excluidos hubieran tenido pequeños lotes en el Ática que podrían haber conservado tras las reformas de Antípatro. Por el contrario, si 9.000 es la línea de separación de los más ricos respecto de todos los demás, esto supondría una élite muy amplia en número que relegó a quienes no alcanzaron ese alto límite censitario introducido por las medidas de 322/21, incluso a los que habrían poseído una riqueza que podría valorarse como intermedia.

Existen al menos dos problemas en esta discusión. El primero apunta a la composición de la riqueza que se habría tomado en cuenta para determinar el número de atenienses habilitados para detentar los derechos plenos de ciudadanía. La segunda cuestión radica en la superficie efectivamente disponible para la producción agraria en sentido amplio (es decir, cualquier tipo de producción llevada a cabo), en caso de que se dé por válida la idea que aquí sostenemos en cuanto a que el censo tomaba como referencia la propiedad de la tierra. Esto no significa que se aplicara a un patrimonio consistente solo en este tipo de riqueza sino que, una vez fijada la pauta de referencia, podía luego adaptarse y aplicarse a cualquier otro patrimonio visible y comprobable. Puesto que la evidencia no es conclusiva al respecto, nuestra demostración se basará necesariamente en ciertas inferencias lógicas a partir de las fuentes.

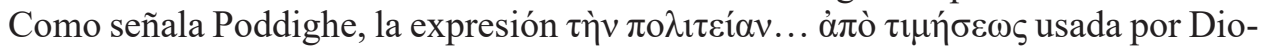
doro se refiere a la instauración de un censo para la participación política, mientras

27 Cf. [Lys.], 20.13: Polístrato incluyó a 9.000 en la lista confeccionada para entregar el poder a "los 5.000 ".

28 Poddighe 2002, 132-140.

29 BAYLiss 2011, 68-73 (cita en 72). 
que Plutarco, en el capítulo previo al ya citado, dice que Antípatro puso como condición que los atenienses se gobernaran mediante la constitución ancestral basada en el

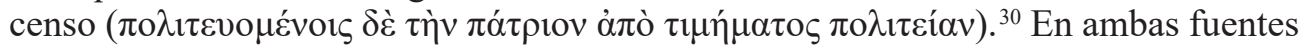
se aclara que los que no llegaban al censo fijado podían marcharse a Tracia para ob-

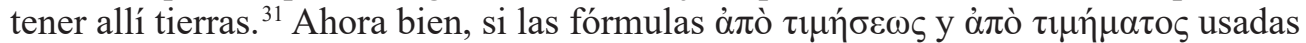
por uno y otro no denotan estrictamente la propiedad de la tierra sino el patrimonio poseído, expresado en general en valores monetarios, el hecho de que a los excluidos de la ciudadanía se les ofreciera tierra podría servir de indicio para dilucidar sobre qué base se hacía el cálculo de la riqueza requerida por el censo.

Poddighe insinúa sugerentemente que los atenienses que habían perdido la ciudadanía plena habrían conservado sus pequeñas parcelas, puesto que, según Diodoro,

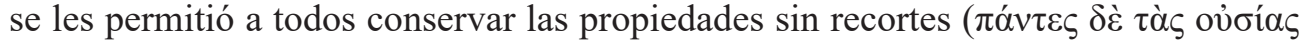

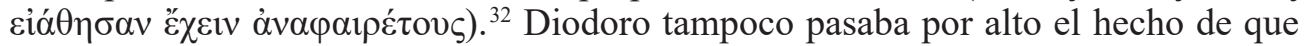
no todos se marcharon a Tracia sino solo los que quisieron hacerlo, lo cual supone que muchos atenienses permanecieron en Atenas aun después de haber perdido los derechos políticos. Plutarco lo señala explícitamente: unos se quedaron y otros se marcharon, situaciones ambas que resultaban igualmente humillantes tanto para unos como para otros. ${ }^{33}$ Es probable que los que permanecieron conservaron sus haciendas (que seguirían trabajando de la misma forma que antes del cambio introducido por Antípatro) y que la mayoría de los que partieron fueron los pobres sin tierras, que quizás constituyeran aquellos a quienes, según Diodoro, se veía como "perturbadores de la paz y belicosos", tal vez asociados con la posibilidad de un retorno de la democracia radical.

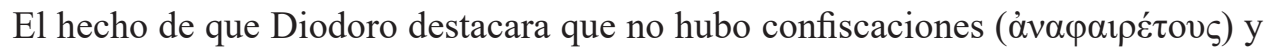
que todos retuvieron sus posesiones sería un indicio de que la riqueza requerida por el censo se habría calculado sobre la base de la propiedad de la tierra, y que una vez establecido esto no se expropió a ninguno sino que se cercenaron los derechos ciudadanos, puesto que el objetivo era precisamente ése: establecer los derechos a partir de la propiedad; circunscribir el cuerpo de ciudadanos conforme al censo; excluir a los incapaces de lograr el censo de la participación política, no de los recursos económicos; si entre éstos se incluía un lote de tierra, continuar en posesión del mismo en función de la propia subsistencia pero sin contar como ciudadano.

30 Plu., Phoc., 27.5; cf. Poddighe 2002, 102-104, 132-134.

31 Diodoro emplea el término $\chi \omega ́ \rho \alpha$; Plutarco usa el vocablo $\gamma \tilde{\eta}$.

32 D.S., 18.18.5; PodDighe 2002, 133, 137.

33 Plu., Phoc., 28.4; PodDighe 2002, 75-107. D.S., 18.18.5, dice que todos los atenienses por debajo del censo mínimo fueron removidos de su tierra natal, una exageración que queda limitada por lo que Diodoro afirma en el pasaje previo. Del censo de Demetrio y la cantidad de atenienses incluidos se deduce que no todos los excluidos previamente migraron a Tracia en 322 (D.S., 18.18.4-5; Plu., Phoc., 28.4). En este marco, hay que recordar que cuando los samios exiliados retornaron a Samos (323/22) muchos atenienses debieron entonces regresar a Atenas (D.S., 18.18.6; 18.18.9). La breve restauración democrática de 318 permitió el retorno de muchos atenienses asentados en Tracia (D.S., 18.55.2-4; 18.65.6; 18.66.4-6; Plu., Phoc., 33.1-2; 34.2; IG II ${ }^{2}$ 448). Cf. Ste. Croix 1981, 301, 609-610, n. 2; Hansen 1985, 28; Oliver 2007, 80-81; BaYliss 2011, 98-101; vAN WEES 2011, 101-102. El censo de 1.000 dracmas instaurado por Demetrio y alcanzado por 21.000 atenienses también implicó la exclusión de una parte, aunque en una proporción sensiblemente menor que en el censo de Antípatro. 
Como hemos indicado, Poddighe propone que la riqueza para llegar al censo mínimo no se componía solo de tierras sino que también se tomaba en cuenta otros bienes, verosímilmente aquellos que pudieran comprobarse de manera fehaciente (la casa, la dote de la mujer, los esclavos); y destaca que la palabra ov̉oía usada por Diodoro para referirse al patrimonio no remitiría únicamente a la tierra. ${ }^{34}$ Pero, como ya vimos, es precisamente al usar este vocablo cuando Diodoro Sículo dice que no hubo confiscaciones, hecho que Poddighe correctamente asocia con la propiedad de tierras ( $\sin$ exclusión de bienes muebles cuando su contabilidad no fuera muy compleja). La autora también indica que, dado que se imponía una restricción al derecho de ciudadanía, los atenienses procurarían demostrar que tenían la riqueza suficiente para ser parte de quienes mantendrían sus derechos. Si el registro de la propiedad de la tierra ya resultaba complejo en una sociedad como la ateniense, que dependía probablemente del control que pudiera efectuarse en los demos (a cargo de los demarcos, con la colaboración de los miembros de los demos, conocedores de la situación en sus propias localidades), ${ }^{35}$ la posibilidad de establecer un censo exhaustivo de la riqueza mueble entre quienes pretendían que se los incluyera dentro del nuevo cuerpo de ciudadanos sería demasiado compleja y llevaría a largas el asunto, en el marco de una reforma que, necesario es recordarlo, buscaba instaurar una oligarquía y dejar fuera del gobierno al 60 o $70 \%$ de los atenienses. ${ }^{36}$

Por ende, teniendo en cuenta la mayor facilidad para determinar el censo sobre la base de la propiedad de la tierra (en la economía visible) ${ }^{37} \mathrm{y}$, sobre todo, la importancia de la que seguía gozando esta condición para delimitar las prerrogativas políticas de los ciudadanos a partir de la posición socioeconómica, más aun en el marco de una oligarquía, la posesión de tierras a una escala suficiente debió de haber sido, como en otras situaciones, el criterio principal para fijar quiénes conservarían los derechos políticos y quiénes serían excluidos de la ciudadanía. Esto no significa que se desdeñara la riqueza mueble sino que el registro de una propiedad agraria que pudiera permitirle

\footnotetext{
34 Poddighe 2002, 132-134, 137-138.

35 Finley 1951, 13-15 y 206-210, nn. 16-26: no hubo un catastro del Ática. Cf. Brun 1983, 6; OsBORNE 1985, 76; GABrielsen 1986, 113, n. 40; ID. 1994, 53; Christ 1990, 158. FAraguna 1997; ID. 2000, demuestra que en Atenas había registros en los demos, sugerencia planteada brevemente por WALBANK 1982, 86, n. 28, 96. La posición de Faraguna también pone en debate el problema de las fronteras de los demos, analizado según visiones antitéticas por THOMPSON 1971 y LANGDON 1985. Si la fijación de los límites entre los demos supone que se comportaran como unidades territoriales, esto implica asimismo su capacidad no solo de determinar sus territorios respectivos sino también de controlar y llevar un registro de su tierra; cf. NEMEs 1980 y el reciente análisis de PAPAZARKAdas 2011, 111-162, que acepta la postura de Faraguna (en 161; cf. 232-233, 235). El registro bien pudo articularse en los demos a partir del rol de los vecinos, como reconocía FINLEY 1951, 14, aunque sin aludir a los demos. Para GABrielsen 1994, 57, en los demos los vecinos conocían bien la riqueza en tierras de sus miembros. Una inscripción del demo de Pireo ( $I G \mathrm{II}^{2}$ 1214.25-26), de fines del siglo IV o inicios del III, muestra que un hombre de otro demo fue requerido para pagar tasa porque poseía propiedad allí. En el marco de la proeisphorá de 362, [D.], 50.8-9, destaca que Apolodoro, hijo de Pasión, tenía propiedades en tres demos diferentes. Cf. [D.], 42.21-23; WALlaCe 1989. No es casual que fueran los miembros de los demos quienes llevaran a cabo, junto a los demarcos y los consejeros, la tarea de establecer las listas con la relación de las propiedades que los ciudadanos poseían. Cf. Jones 1957, 28; Ste. Croix 1953, 60; BrUN 1983, $37-38$.

36 Sobre la dureza de la oligarquía de Antípatro, BAYLiss 2011, 69-71; cf. LAPE 2004, 40-42.

37 Nuestra perspectiva deja necesariamente afuera el problema de la economía invisible, imposible de estimar por su propio carácter; cf. GABRIELSEN 1986; ID. 1994, 53-60; CoHEN 1992, 191-207; FERRUCCI 2005.
} 
a un ateniense cumplir con el censo establecido debió de haber actuado como referencia inmediata. De otro modo, se hacía necesario mostrar qué otra riqueza podía suplantar la carencia de tierras, o suplementar una hacienda rural insuficiente.

\section{Un posible patrón entre valor monetario y unidad de superficie}

Aun si las estimaciones de la riqueza aparecen expresadas en valores monetarios (dracmas, minas, talentos), la propiedad de la tierra fue la riqueza principal para establecer el censo. En este sentido, un factor que autoriza a traducir tales cantidades monetarias a propiedades de tierra es el tímema del Ática, basado evidentemente en la referencia de la distribución de las propiedades agrarias y estimado en 6.000 talentos para el conjunto de los contribuyentes. ${ }^{38}$ Lo cual permite, como veremos, conjeturar sobre el reparto de la tierra dentro de este grupo, en la medida en que pagaban un porcentaje (entre 1 y $2 \%$ ) de la riqueza declarada, o exteriorizada, a partir de controles como los que pudieron haber existido en los demos. Si bien tenemos la posibilidad de acceder a ciertos precios de lotes, a partir de ventas de tierras públicas, o de propiedades confiscadas conducidas por los poletaí, no hay mucho para inferir de manera prudente, más allá de datos aislados, sobre la compra-venta de tierras entre privados; también los datos de las estelas sobre arrendamientos brindan pautas a tomar en cuenta. ${ }^{39}$

La cuestión radica, pues, en relacionar importes monetarios como los que se consideran en los censos de 322/21 y 317/16 con posibles propiedades agrarias. El punto central consiste en estimar el valor de referencia de la unidad de superficie que pudo haber servido de base para la estimación de los lotes, a fin de llegar a las 2.000 dracmas del censo de Antípatro, que posteriormente debió de ser tomado en cuenta por Demetrio de Falero al establecer un censo mínimo de 1.000 dracmas. En este contexto, las rationes centesimarum, inscripciones que indican el cobro de una tasa del $1 \%$ en las ventas de tierras de grupos corporativos (fratrías, demos, etc.) a particulares atenienses, nos van a permitir realizar ciertas conjeturas a partir de lo que parece haber sido una constante usada por la polis para las ventas públicas.

A partir de las rationes centesimarum, Vladislav Andreyev ${ }^{40}$ arribaba a la conclusión, que muchos especialistas retoman, ${ }^{41}$ de que en la Atenas del siglo IV el precio de un pléthron de tierra habría sido de 50 dracmas, conforme a una constante utilizada por la administración ateniense. Aplicado a los censos, esto supone que en 322/21, al imponer un mínimo de 2.000 dracmas para conservar la ciudadanía plena y participar del gobierno, Antípatro estuviera apuntando a restringir el cuerpo de ciudadanos

38 D., 14.19; 14.27; Philoch., FGrHist 328 F 46, apud Harp., s.v. ö $\iota_{1} \dot{\varepsilon} \xi \alpha \kappa 1 \sigma \chi i ́ \lambda \iota \alpha$; Plb., 2.62.7.

39 Precios de lotes de tierra: PRITCHETt 1956, 269-276; ventas de tierras públicas: LeWIS 1973; ANDREYEV 1974; LAMBERT 1997; ventas de tierras confiscadas: WALBANK 1982; arriendos de tierras públicas: WALBANK 1983; ID. 1984; OsBoRne 1988, 281-292; Williams 2011; arriendos de tierras privadas: OsBORNe 1988, 304319.

40 ANDREYEV 1974, 14-18.

41 Cf. Burford 1977/78, 169-171; JAMESON 1977/78, 125, n. 13; Hanson 1995, 188 y 478-479, n. 6; Poddighe 2002, 137; van WeEs 2006, 357-358 y n. 34. 
a aquellos que poseyeran lotes de tierra de un mínimo de 40 pléthra, es decir, 3,6 ha. Considerando estos números, se puede estimar que desde 317/16 en adelante, a partir del acuerdo de paz propiciado por Casandro, el censo de 1.000 dracmas requerido durante la regencia de Demetrio de Falero suponía contar con una riqueza mínima en tierras de 20 pléthra, esto es, 1,8 ha. Puesto que, como ya vimos, entre los censos de Antípatro y de Demetrio se habría pasado de los 9.000 ciudadanos indicados por Diodoro a los 21.000 según el texto de Ctesicles, habría que admitir una masa de alrededor de 12.000 atenienses que contarían con propiedades agrarias de entre 1,8 y 3,6 ha. O, al menos, se debía demostrar la posesión de otro tipo riqueza que llegara a los mínimos exigidos.

El valor de 50 dracmas que Andreyev interpretaba como el precio fijo para un pléthron de tierra ha tenido aceptación entre los estudiosos, aunque también ha recibido algunas críticas que nos permitirán determinar la validez de traducir los valores monetarios a unidades de superficie de tierra conforme al análisis de los precios de los lotes en el Ática del siglo IV. David Lewis discutía ciertos aspectos de la propuesta de Andreyev pero en general aceptaba su explicación..$^{42}$ Recientemente, Stephen Lambert ha analizado la cuestión, proponiendo que "la periodicidad de los precios" que se verifica en los documentos ${ }^{43}$ pudo obedecer a que la polis no utilizara precios fijos sino precios mínimos o una escala de precios mínimos por pléthron, aunque no hay otros casos conocidos. ${ }^{44}$ Así, se lograría el objetivo de maximizar los ingresos por venta de tierras; y los casos en que las cantidades no siguen la pauta periódica se explicarían fácilmente como ventas en las que se habría pagado más que el mínimo (para khoría y eskhatiai los mínimos serían diferentes). Lambert también cita la propuesta de Sally Humphreys, ${ }^{45}$ quien planteaba que la periodicidad reflejaría la práctica, atestiguada también en los arriendos, de computar el valor capitalizado de la tierra a razón de 12,5 veces su renta anual que, como señala Lambert, podía ser el valor real o potencial de una propiedad según el conocimiento, claro está, de la productividad de la tierra dentro de una región determinada. Esto supone un retorno 1974.

42 LewIS 1973, 188-197. El autor cita dos publicaciones en ruso que conocemos a través de ANDREYEV

43 En su mayoría, los valores se rigen por el módulo de 50 dracmas o fracciones del mismo (e.g. 12,5; $6,25)$.

44 LAMBert 1997, 229-233, 257-265, esp. 262-263.

45 Humphreys 1978, 289-290, n. 19; OSBORNE 1985, 56-57; LAMBERT 1997, 263. La pauta resulta compatible con la subasta de tierras (Lambert la considera poco probable), pues el cálculo basado en el criterio de 12,5 veces la renta anual estipularía el carácter aceptable de una oferta. En caso de que se hubiera aplicado la subasta, podría tener asidero la sugerencia de LEWIS 1973, 195, sobre que la periodicidad surgiría del uso de intervalos de oferta estándares basados en la pauta de 12,5, pero asumiendo un valor mínimo fijado a partir del procedimiento señalado por Humphreys. Pero no siempre se terminaría respetando la periodicidad, y por eso habría valores que no se ajustarían a la pauta. Asimismo, podría haber actuado como referencia de los precios mínimos a pagar en la venta directa de tierras (diferentes para los khoría y las eskhatiai, como dijimos), conforme, claro está, a los valores potenciales o reales de una propiedad en una región dada, habiendo casos en que se terminaría pagándo más, sin atenerse entonces al valor mínimo de referencia fijado a partir de la pauta de 12,5. La venta directa o la subasta pudieron aplicarse en una caso u otro, ambos métodos articulados sobre la base de un precio mínimo, calculado a partir de computar el valor capitalizado a razón de 12,5 veces la renta anual de la tierra. 
del $8 \%$ anual, que en general los estudiosos han asumido como una renta plausible, aunque conservadora, en relación con la propiedad de una tierra. ${ }^{46}$

Todo esto implica que, desde el punto de vista del cálculo de la riqueza en tierras que podía servir de base para un censo, una superficie de un pléthron se tradujera en un valor de 50 dracmas, u otras equivalencias con valores agregados a razón de 12,5 dracmas para un cuarto de pléthron, al margen de que, en la compra-venta de tierras entre propietarios privados, los precios de mercado variaran según las condiciones específicas de los lotes, su ubicación, etc. Así pues, el precio orientativo de 50 dracmas, y no el precio real en el mercado, ${ }^{47}$ por cada pléthron para las ventas públicas de tierras debió de haber operado como referencia, con el problema complejo, bien señalado por Lambert ${ }^{48}$ de si puede hablarse de un mercado.

Como precio mínimo o como valor capitalizado a razón de 12,5 veces la renta anual, si esta periodicidad se aplicaba a las ventas bien pudo ser una referencia para establecer los censos mínimos de 2.000 y 1.000 dracmas en 322/21 y 317/16, respectivamente. De esto se seguiría que, no como precio real sino como pauta para el cálculo, el valor de 50 dracmas por pléthron pudo haber sido una pauta factible para traducir propiedades de tierra a hipotéticos valores monetarios. Sin ser un precio fijo, de todos modos, esta constante pudo servir para establecer, en función de ambos censos, la pertenencia a un sector con una riqueza de 2.000 dracmas o más, o de 1.000 dracmas o más. Pero no solo sería un indicio válido para traducir unidades de superficie a valores monetarios para los censos de Antípatro y Demetrio, sino también para los importes de los patrimonios de los atenienses con más riqueza. Se trataría de un patrón orientativo, configurado a partir de una pauta de administración de la polis, que nos permitiría conjeturar de manera tentativa qué cantidad de tierra podía implicar aproximadamente una riqueza monetaria dada y que nos serviría para pensar los promedios de los diferentes sectores, no las haciendas reales de los terratenientes, o los labradores acomodados o los más pobres, además de que no todos poseían el patrimonio completa y necesariamente en tierras.

\section{Calculando la distribución de la tierra}

A partir de esta información, referida a la situación de fines del siglo IV pero extrapolada a otros contextos de la historia ateniense por varios de los autores citados, vamos a presentar una reformulación de las propuestas sobre la distribución de la propiedad de la tierra en la Atenas posterior a la Guerra del Peloponeso. Dejando de lado por

46 Is., 11.42: renta anual de $8 \%$, semejante a la de las casas; $I G \mathrm{II}^{2} 2496$, consigna una renta anual de 7,7\%. Otras actividades generaban retornos más elevados; en el pasaje citado, Is., 11.42, también señala que un préstamo de dinero arrojaba un $18 \%$ de interés. Claro está, estas inversiones eran más riesgosas.

47 Por ejemplo, según se infiere de Lys., 19.29; 19.42, el precio por cada pléthron de tierra de la propiedad de 300 pléthra mencionada es de 83 dracmas. Como dice LAMBERT 1997, 233, es posible que los precios que se perciben a partir de las rationes centesimarum se determinaran tanto por factores sociales ligados a obligaciones y favores como por los factores económicos de oferta y demanda y la calidad y el tamaño de las haciendas.

48 LAmbert 1997, 231-232. 
ahora las discrepancias entre Diodoro y Plutarco en cuanto a la cantidad de excluidos por las reformas de Antípatro, ${ }^{49}$ los números relativos a los atenienses incluidos en la ciudadanía y su riqueza expresada en el tamaño de los lotes de tierra nos dan ciertas pautas para conjeturar sobre la viabilidad de estos guarismos, tanto en cuanto a la población como en cuanto a la distribución de las parcelas y la cantidad de atenienses desposeídos de la tierra. Partiendo de un total de 30.000 ciudadanos y asumiendo la persistencia de unos 5.000 atenienses sin tierra alguna desde finales del siglo $\mathrm{V}$, esto implica que cerca de 25.000 tendrían alguna propiedad..$^{50}$ Es evidente que para establecer nuestro modelo debemos prescindir de las fluctuaciones en el total de la población ciudadana adulta y asumir como constante el número de atenienses sin tierras; aunque es factible que, si el número de 5.000 ciudadanos sin propiedades es aceptado, pudiera haberse producido un aumento de pobres sin tierras a lo largo del siglo IV, y en especial en la segunda mitad de dicho período. ${ }^{51} \mathrm{~A}$ los fines del cálculo, vamos a asumir que todos los que quedaron incluidos entre los 25.000 poseyeron efectivamente tierras, aunque está demostrado que esto no ocurría así incluso dentro del sector de los atenienses ricos; aceptado este punto, procederemos a traducir a propiedades agrarias los niveles de riqueza expresados en las fuentes en términos monetarios. Además, partiendo de un total de 30.000 atenienses varones adultos admitiremos junto a Jameson y Foxhall la existencia de en torno a 22.000 hogares, puesto que en una parte de éstos podían convivir al menos dos adultos: padre e hijo, o hermanos. ${ }^{52}$ Asumimos que por cada tres hogares habría cuatro ciudadanos varones adultos, es decir, de cada tres hogares dos de ellos tendrían un adulto cada uno y el restante dos adultos. Al referirse a los ciudadanos sin tierras, Foxhall descuenta directamente 5.000 del total de hogares propuesto; pero en el comentario de Dioniso de Halicarnaso la cifra parece remitir a cantidad de población, ${ }^{53}$ por lo que también en este caso debemos estimar un número de hogares que resulta necesariamente inferior al de la población comprendida en este conjunto.

En función del cálculo, cabe aplicar a cada grupo la misma ratio entre número de hogares y cantidad de ciudadanos, de lo cual se colige que los 5.000 sin tierra alguna formarían parte de cerca de 3.750 hogares. Cabe admitir entonces la existencia de 18.750 hogares que incluirían a 25.000 adultos y contarían con alguna propiedad agraria. Si el censo poblacional de 21.000 ciudadanos atestiguado por Ctesicles implica a todos los ciudadanos con el mínimo de riqueza de 1.000 dracmas impuesto por Demetrio para la ciudadanía plena, puede asumirse entonces que del total de 30.000

49 Cf. Hansen 1985, 28-36; van WeEs 2011, 107-110.

50 Como ya indicamos, muchos atenienses que no llegaron al censo retuvieron sus tierras, pues Antípatro apuntó a la exclusión política. Así, junto a los 9.000 con 2.000 dracmas o más se asume la presencia de unos 21.000 .

51 Mossé 1973 revisa su análisis previo (ID. 1962, 43-54) y señala un declive del campesinado en la segunda mitad del siglo IV; ver VALDÉs Guía 2015. Cf. AUDRING 1974 sobre los límites a la concentración de la tierra.

52 JAMESON 1977/78, 125; FoxHALl 1992, 156; cf. GOMmE 1933, 26. El ciclo vital de los hogares propuesto por GALlant 1991, 22-30, abona la idea de que el número de varones adultos sería siempre mayor que la cantidad de hogares. Cox 1998, 109, 141-143, retoma el modelo de Gallant; cf. D., 53.6; 53.10; Lys., 18.14; 18.20-21.

53 D.H., Lys., 32; cf. Foxhall 1992, 156 y n. 21. 
atenienses habrían quedado despojados de sus derechos los 5.000 sin tierras y otros 4.000 con propiedades valuadas por debajo del mínimo establecido. Realizando un cálculo proporcional a partir de la ratio entre 25.000 adultos y 18.750 hogares con tierras, y asumiendo la presencia de 4.000 atenienses con propiedades por debajo del censo de 1.000 dracmas, se obtiene que estos últimos integrarían unos 3.000 hogares con parcelas inferiores a 1,8 ha, que es la ecuación que surge de traducir 1.000 dracmas en un lote de tierra conforme al precio de 50 dracmas por pléthron anteriormente argumentado. Puesto que entre el censo de Antípatro y el de Demetrio la diferencia en el número de atenienses adultos incluidos en el cuerpo de ciudadanos es de 12.000, teniendo en cuenta que en el primer censo habría 9.000 atenienses con una riqueza de 2.000 dracmas o superior y en el segundo unos 21.000 con una riqueza de 1.000 dracmas o más, entonces estos 12.000 atenienses debieron de haber tenido un patrimonio de entre 1.000 y 2.000 dracmas, es decir que habrían contado con lotes de entre 1,8 y 3,6 ha y, proporcionalmente, formarían parte de unos 9.000 hogares.

En cuanto a los atenienses más ricos, Foxhall parte de las constataciones de John Davies, pero incrementa sin argumento alguno el número de ciudadanos dentro de este grupo hasta alcanzar 2.000 hogares. En el siglo IV, según Davies, habría alrededor de 300 atenienses que pagaban liturgias, incluyendo las exenciones, o unos 1.200 según Peter Rhodes (que revisa y critica los criterios del primero proponiendo que éste sería el panel total sobre el que se realizarían las exenciones), incluyéndose en este grupo a quienes poseían 3 talentos o más. ${ }^{54} \mathrm{Al}$ tratarse de imposiciones sobre el patrimonio, estos números harían referencia a hogares ${ }^{55}$ Por otra parte, los atenienses con fortunas de un talento o más serían ya parte de la clase ociosa, que Davies estimaba en unos 1.200 y Rhodes en alrededor de 2.000. Si 2.000 dracmas se traducen en una propiedad de 3,6 ha, entonces una riqueza de un talento implica 10,8 ha y 3 talentos equivalen a 32,4 ha. Los cálculos de Davies suponen una clase propietaria rica más reducida que la que plantea Rhodes, cuya visión en términos de cantidad de ciudadanos se acercaría a la de Foxhall, que hablaba de 2.000 hogares ricos, una mitad con lotes de entre 20 y 50 ha y la otra mitad con lotes de entre 10 y 20 ha. Ante estas divergencias en la cantidad de hogares y de ciudadanos ricos tanto de la clase litúrgica como de la clase ociosa, y en vista de los argumentos de varios estudiosos sobre las posiciones de Davies y Rhodes, ${ }^{56}$ es necesario que nos detengamos en una serie de consideraciones respecto de estas cuestiones.

54 Davies 1971, xxiii-xxiv; ID. 1981, 28-37; RHODEs 1982.

55 Dos o más ciudadanos de un mismo hogar solo pagaban las liturgias correspondientes al patrimonio sujeto a tributación, pero en el registro figuraría cada ciudadano nominalmente alcanzado por la obligación: Lys., 18.21; cf. Isoc., 18.60. Isoc. 15.145, señala que padre e hijo, siendo parte de los 1.200, pagaron eisphorai, trierarquías y otras liturgias; esto implica que, aunque figuraran ambos, el patrimonio habría sido tasado solo una vez según las cargas a pagar. Como las trierarquías y demás liturgias se aplicaban a patrimonios ligados a hogares, se debe considerar que los 300 más ricos y los 900 siguientes hasta sumar los 1.200 consignados en las fuentes implican cantidades de hogares, calculando una mayor población dentro de los mismos siguiendo la pauta indicada.

56 Siguen a Davies: Ruschenbusch 1978; ID. 1987; Mossé 1979; Strauss 1986, 42; Ober 1989, 128 ; Kron 2011, 129-131; a Rhodes: Christ 1990, 149-150 y n. 11; HANSEN 1991, 112-115; Gabrielsen 1994, 178-180; Poddighe 2002, 128-129. Problemas en ambas visiones: MacDowell 1986; Wallace 1989, 479 y n. 19. 
Es pertinente tomar en cuenta aquí las discusiones sobre cuántos serían los atenienses que pagaban la eisphorá en el siglo IV. Este tributo permite establecer un tímema del Ática de 6.000 talentos relativo al conjunto de los eisphérontes. No se trata de un valor absoluto, pero permite hacer conjeturas sobre el reparto de la riqueza dentro de este grupo de contribuyentes, en la medida en que pagaban un porcentaje de la riqueza declarada, o exteriorizada a partir de controles como los que pudieron haber existido en los demos. Según la cantidad de tributarios a la eisphorá que se considere, ${ }^{57}$ con un tímema del Ática de 6.000 talentos, partiendo de los atenienses más ricos y descendiendo en la pirámide social para incluir a los poseedores de una riqueza intermedia, esto nos permite conjeturar cómo pudo estar distribuido dicho tímema entre ese conjunto de contribuyentes. Considerando la riqueza mínima de cada sector, se debe entonces adaptar los posibles patrimonios de los atenienses que debían pagar la eisphorá ajustando su participación en el tímema de 6.000 talentos. Para los sectores que no pagaban este tributo se procede a estimar una riqueza promedio tomando en cuenta los mínimos y los máximos que delimitan cada rango de riqueza; de otra forma se llegaría a situaciones en las que el promedio se ubicaría por encima del mínimo del sector inmediato superior.

A partir de esto, presentamos aquí un modelo que toma en cuenta los debates sobre la eisphorá, la proeisphorá y las liturgias. Según puede desprenderse de las fuentes, la eisphorá abarcaba a un sector más amplio que los 1.200 que afrontarían todas las cargas.$^{58}$ Rhodes propone que 2.000 pagaban eisphorá $;{ }^{59}$ Vincent Gabrielsen asume que 1.200 es una cifra "demasiado baja", siguiendo a Augustus Boeckh para quien "muchos otros" junto a los 1.200 pagaban esta contribución. ${ }^{60} \mathrm{Si}$ asumiéramos provisoriamente la hipótesis de que el tímema de 6.000 talentos se lograba con el aporte de los 3.000 atenienses más ricos (Fig. 3, sectores 1-3), distribuidos según la relación de cuatro adultos cada tres hogares que hemos formulado, el total de hogares para estos 3.000 ciudadanos sería de 2.250 , cercano a la conjetura de Rhodes. ¿Son estos $2.000 / 2.250$, esto es, $800 / 1.050$ más por encima de los 1.200 , una cifra que incluye a "muchos otros" y no es "demasiado baja" para el pago de la eisphorá? Miriam Valdés Guía ha analizado la información que presenta Demóstenes, retomando las explicaciones de Arnold Jones y Geoffrey de Ste. Croix acerca de que, con la reforma de la eisphorá de 378, la riqueza mínima requerida para ser contribuyente sería de 25 minas (2.500 dracmas) y la cantidad de ciudadanos alcanzados por el pago de este tributo sería de $6.000 .{ }^{6}$ Según la proporción entre varones adultos y hogares que aquí

57 Los diversos cálculos surgen de las distintas visiones planteadas; 1.200 contribuyentes: RUSCHENBUSCH 1978; ID. 1987; Mossé 1979; KRON 2011, 129-131; 2.000 tributarios: Rhodes 1982; 6.000 contribuyentes: Jones 1957, 28-29, 83-85; Ste. Croix 1953, 33; Brun 1983, 19-22, 64-73; MARKLe 1985, 282; VALdÉs Guía 2014.

58 Cf. D., 20.26-28; Isoc., 15.145.

59 Rhodes 1982, 7-8.

60 BoeckH 1842², lib. IV, cap. 9, 526-532, en 530; GABrielsen 1994, 189-190. Cf. Thomsen 1964, $200-$ 201.

61 D., 27.7; 28.4; 29.59; VALdés Guía 2014, 252-253, 256-257, 268; Jones 1957, 28-30, 84; STE. CROIX 1953, 33. Cf. D., 22.60, sobre el reclamo por un pago atrasado de 34 dracmas por una eisphorá; de esto se colegiría un patrimonio de 34 minas si la tributación se hubiera realizado usando una tasa del 1\%. Ver BoECKH $1842^{2}, 531$. 
utilizamos, estos 6.000 atenienses formarían parte de unos 4.500 hogares cada uno de ellos con una riqueza de por lo menos 2.500 dracmas.

A partir de Davies, se considera que los 3 talentos son un mínimo indicativo para los 300 atenienses más ricos, ${ }^{62}$ que pueden equipararse al grupo de los proeisphérontes. ${ }^{63}$ Las sumas afrontadas por estos 300 debieron de haber sido elevadas, sobre todo a partir de la institución de la proeisphorá, sumada a la trierarquía y las demás liturgias; por ende, la riqueza mínima requerida debió de estar en los 3 talentos o más, pues como puede deducirse de Davies es probable que quienes poseyeran menos que 3 talentos no asumieran las cargas más gravosas. Pero no todos han coincidido con la idea de un límite bien establecido; Douglas MacDowell piensa que era un resultado práctico; Gabrielsen plantea la imposibilidad de decidir un nivel mínimo de riqueza a partir del cual un ateniense quedaba integrado en la clase litúrgica y un nivel mínimo a partir del cual formaba parte de la clase ociosa, tal como planteaba Davies. ${ }^{64}$ Dentro de este sector (que aquí asociamos a los 300 a cargo de la proeisphorá y no a todos los miembros de la clase litúrgica) había patrimonios superiores a los 3 talentos, como muestra la evidencia. ${ }^{65}$ Para realizar los cálculos, Geoffrey Kron conjetura en su análisis que había unos 30 atenienses con unos 15 talentos. ${ }^{66}$ Esto es compatible con nuestro esquema.

Tomando 3 talentos como riqueza mínima para los 300 hogares más ricos y 1,5 talentos para los 900 hogares ricos inmediatamente por debajo ${ }^{67}$ considerando los números ya vistos ligados a los censos de Antípatro y Demetrio y asumiendo que pagaban la eisphorá los 6.000 atenienses con 25 minas o más de riqueza, se obtiene el siguiente cuadro (Fig. 2, provisorio):

62 Davies 1971, xxiii-xxiv; ID. 1981, 17 ss., 28-37. Cf. Hansen 1991, 113. Sobre los 300: D., 18.103; 18.171; 50.9; [D.], 42.3-5; 42.25; Aeschin., 3.222; Is., 6.60.

63 Thomsen 1964, 235; Davies 1981, 19; Rhodes 1982, 6-7. Cf. MacDowell 1986, 445-449; Wallace 1989; GABRIELSEN 1994, 53-58, 70-72, 116-117, 189-193, 210-217; VALDÉS Gú́A 2014.

64 MacDowell 1986, 443-444; Gabrielsen 1994, 45-53. De algunas fuentes se deduciría que atenienses con 2 talentos, o incluso menos, pudieron pagar la trierarquía y ser parte de la clase litúrgica (D., 27.64; Is., 5.35-36); otra evidencia relaciona a poseedores de más de 8 talentos con los que ejecutaban las liturgias (X., Oec., 2.3 ss.).

65 Cf. Demóstenes, 14/15 talentos: D., 27.11; 29.59. Onetor, 30 talentos: D., 30.10. Timoteo, 17 talentos: [Arist.], Oec., 1350b 1 ss.; Ar., Pl., 180 (con escolio); Lys., 19.40; cf. D., 27.7; 29.59.

66 Kron 2011, 131.

67 Esto coincide con las estimaciones de KRON 2011, 129-131 (para Davies, un talento era el mínimo para la clase ociosa). Justificamos este criterio en la posibilidad, destacada por Gabrielsen, de que los atenienses con alrededor de 1,5 talentos pudieran haber pagado la trierarquía, aun cuando esto fuera algo ocasional. 
Figura 2. Datos sobre población, riqueza y distribución de la tierra.

\begin{tabular}{|c|c|c|c|c|c|}
\hline Sector & $\begin{array}{c}\text { Cantidad } \\
\text { hogares }\end{array}$ & $\begin{array}{c}\text { Cantidad } \\
\text { ciudadanos }\end{array}$ & Riqueza mínima & $\begin{array}{c}\text { Tamaño } \\
\text { de lotes }\end{array}$ & $\begin{array}{c}\text { Lote } \\
\text { promedio }\end{array}$ \\
\hline $\mathbf{1}$ & 300 & 400 & $18.000 \mathrm{dr}$. & 32,4 ha ó más & $>32,4$ ha \\
\hline $\mathbf{2}$ & 900 & 1.200 & $9.000 \mathrm{dr}$. & $16,2-32,4$ ha & 24,3 ha \\
\hline $\mathbf{3}$ & 3.300 & 4.400 & $2.500 \mathrm{dr}$. & $4,5-16,2 \mathrm{ha}$ & 10,4 ha \\
\hline $\mathbf{4}$ & 2.250 & 3.000 & $2.000 \mathrm{dr}$. & $3,6-4,5$ ha & 4,1 ha \\
\hline $\mathbf{5}$ & 8.800 & 12.000 & $1.000 \mathrm{dr}$. & $1,8-3,6 \mathrm{ha}$ & $2,7 \mathrm{ha}$ \\
\hline $\mathbf{6}$ & 2.900 & 4.000 & $<1.000 \mathrm{dr}$. & $0,1-1,8 \mathrm{ha}$ & 1,0 ha \\
\hline $\mathbf{7}$ & 3.700 & 5.000 & $<1.000 \mathrm{dr}$. & 0 ha & 0 ha \\
\hline Total & 22.000 & 30.000 & ----- & ---- & ---- \\
\hline
\end{tabular}

Es posible profundizar aún más el esquema a partir de un argumento planteado en nuestra crítica a van Wees sobre el tamaño de los lotes de los zeugîtai y su integración en "los 5.000" de la revolución oligárquica de 411, grupo amplio que el autor identifica con las tres primeras clases solonianas: pentakosiomédimnoi, hippeîs y zeugîtai, sumando cerca del 17\% de una población de 30.000. ${ }^{69}$ Según Tucídides, los 5.000 se definirían como "los que resultaran más útiles por sus riquezas $(\chi \rho \eta ́ \mu \alpha \sigma \imath)$ y sus personas ( $\sigma \omega ́ \mu \alpha \sigma \mathrm{v})$ )", pasaje que Aristóteles retomaba pero usando el sugestivo verbo $\lambda \eta\rceil \tau o \cup \rho \gamma \varepsilon \tilde{i} v$ para referirse a los servicios que estos ciudadanos debían prestar; Tucídides también indicaba que compondrían estos 5.000 todos aquellos que pudieran procurarse el armamento hoplítico (ő $\pi \lambda \alpha \pi \alpha \rho \varepsilon ́ \chi 0 \nu \tau \alpha \iota) .{ }^{70}$ Según nuestro punto de vista, se trataría de la élite de los hoplitas que estaría integrada por el conjunto de las dos primeras clases al que se habría añadido la parte más rica de la clase de los zeugîtai a partir de la organización de la primera eisphorá. Ahora bien, es probable que al final de la Guerra del Peloponeso el número de los que podían ser alcanzados por la eisphorá hubiera disminuido en consonancia con una baja demográfica en la ciudadanía y cierta disminución patrimonial de muchos atenienses ricos, ${ }^{71}$ ubicando tal vez la cantidad de ciudadanos acomodados en torno a "los 3.000" que en 404 la oligarquía de los Treinta tiranos había instaurado brevemente en el poder. ${ }^{72}$ Según Barry Strauss, este grupo se definía como la clase de los ploúsioi e incluía a todos

68 Una hacienda de 32,4 ha (360 pléthra) se asemeja a la de Fenipo: [D.], 42; STE. Croix 1966; BuRForD 1993, 69-70. Otras similares: Ar., Ec., 592; P1., Alc., 1.123c; Lys., 19.29; 19.42; D., 23.208; FINLEY 1951, 58; HANSON 1998², 43, n. 2; ID. 1995, 186-187, 478, n. 4; para Foxhall 1992, 156-157, había muchas haciendas grandes.

69 VAN WEES 2006, 374; cf. 361.

70 Th., 8.65.3, y 8.97.1, respectivamente; Arist., Ath., 29.5; cf. Lys., 20.13

71 Sobre la disminución de las fortunas, Aeschin., 2.147; D., 23.208; Isoc., 15.161; Lys., 16.10; 19.46-52; 26.22; [Lys.], 20.33; Plu., Moralia, 835A; X. Oec., 20.22-26; Vect., 2.6; 4.6; Brun 1983, 19, 26. ANDREYEV 1974, 20, conjeturaba que las transferencias de propiedades debió afectar sobre todo a los ricos; cf. PEČIRKA $1976,14$.

72 Cf. X., HG, 2.3.18-20; 2.3.48; 2.4.40; Arist., Ath., 36.2; GalleGo - VAldés Guía 2014, 159-160, 177, n. 61 . 
aquellos que poseían un patrimonio de 4.500 dracmas o más, ${ }^{73}$ cifra que implicaría una hacienda de 90 pléthra u 8,1 ha si se acepta, como ya hemos visto, que las 2.000 dracmas del censo de Antípatro se traducirían en una propiedad de 40 pléthra o 3,6 ha. La posesión de 8 ha como base para poder formar parte del grupo de los atenienses ricos se correspondería con la tierra poseída por un zeugítes acomodado, según nuestro ya mencionado análisis de su situación socioeconómica planteado a partir de la crítica a la perspectiva de van Wees. Los atenienses con 4.500 dracmas de riqueza, pero por debajo de un talento, tal vez constituyeran el límite inferior, probablemente fluctuante, entre quienes debían trabajar para vivir y quienes no necesitaban hacerlo, labradores que probablemente pudieran utilizar algunos esclavos. ${ }^{74}$

Ahora bien, según cómo se consideren ambas informaciones cuantitativas sobre el selecto grupo de atenienses, esto es, si hacen referencia a cantidad de hogares o de atenienses varones adultos, obviamente el cálculo se modifica. Tanto de los pasajes de Tucídides y de Aristóteles sobre "los 5.000" como de los de este último y de Jenofonte sobre "los 3.000" se desprendería que se trata del número de ciudadanos habilitados para hacerse cargo del gobierno. Por ende, si para el período posterior a la guerra adoptamos el número de 3.000 atenienses con más de 8 ha o 4.500 dracmas y aceptamos que en los 1.200 hogares más ricos habría unos 1.600 adultos como parte de "los 3.000", se puede pensar entonces que los 1.400 necesarios para alcanzar el número total provendrían de los zeugîtai más ricos, procedentes de una cantidad de hogares que proporcionalmente se ubicaría en torno a las 1.050 unidades. Todas estas disquisiciones apuntan a dimensionar una élite numéricamente más amplia a partir de la posesión de una riqueza que para algunos autores implicaba la pertenencia a la clase ociosa, como es el caso recién citado de Strauss o el propio van Wees, quien cree que la posesión de 8 ha significaba formar parte de la clase ociosa ateniense. Como ya hemos dicho, nuestra diferencia con este último radica en que según su perspectiva todos los zeugitai eran parte de los atenienses ricos, mientras que para nosotros se trataba de una parte minoritaria, que por lo demás se hallaría en una situación socioeconómica limítrofe entre la ociosidad y la necesidad de tener que trabajar para vivir. Estos 3.000 atenienses formarían parte de unos 2.250 hogares, dentro de los cuales estaban los 1.200 que contribuían para las liturgias, en cuyo seno se hallaban a su vez los 300 que pagaban regularmente las liturgias más onerosas, la trierarquía y la proeisphorá.

Los datos recolectados a partir de la documentación y las interpretaciones sobre población, número de hogares, rango del tamaño de los lotes, etc., se vuelcan en las Figs. 3 y $4 .^{75}$

73 STRAuss 1986, 42-43, piensa que 4.500 dracmas eran el límite inferior de la clase ociosa, y que en [D.], 42.22, las quejas por las dificultades para vivir con esa riqueza apuntan a evadir el pago de cargas. OBER 1989, 128-29, n. 59, no cree que formaran parte de los atenienses acomodados; cf. DAVIES 1981, 28, 75; STE. CROIX $1981,115$.

74 JAMESON 1977/78; ID. 1992, 142-145; BuRFORD 1993, 182-222; HANSON 1995, 63-70, 129-130. Cf. Ste. Croix 1981, 120-174, 505-509; Wood 1983; Ober 1985, 22-23; ID. 1989, 24-27; Osborne 1985, $144-$ 145; Gallant 1991, 30-33; Sallares 1991, 56; CARlsen 2002, 120-121 y nn. 22-25.

75 Para su elaboración se toma en cuenta la riqueza mínima necesaria para ser parte de uno de los cuatro primeros sectores, que pagaban la eisphorá [Sector 1: 3 talentos; S. 2: 1,5 T.; S. 3: 0,75 T. (= 4.500 dracmas); 
Figura 3. Cuadro de distribución de la tierra.

\begin{tabular}{|c|c|c|c|c|c|c|}
\hline Sector & $\begin{array}{c}\text { Cantidad de } \\
\text { ciudadanos }\end{array}$ & $\begin{array}{c}\text { Cantidad de } \\
\text { hogares }\end{array}$ & $\begin{array}{c}\text { Tamaño } \\
\text { de lotes }\end{array}$ & $\begin{array}{c}\text { Lote } \\
\text { promedio }\end{array}$ & $\begin{array}{c}\text { Total de } \\
\text { hectáreas }\end{array}$ & $\begin{array}{c}\text { Porcentaje } \\
\text { del área }^{76}\end{array}$ \\
\hline $\mathbf{1}$ & 400 & 300 & 32,4 ha ó más & 43,2 ha & 12.960 & $14,4 \%$ \\
\hline $\mathbf{2}$ & 1.200 & 900 & $16,2-32,4$ ha & 21,6 ha & 19.440 & $21,6 \%$ \\
\hline $\mathbf{3}$ & 1.400 & 1.050 & $8,1-16,2$ ha & 10,8 ha & 11.340 & $12,6 \%$ \\
\hline $\mathbf{4}$ & 3.000 & 2.250 & $4,5-8,1$ ha & 6,0 ha & 13.500 & $15,0 \%$ \\
\hline $\mathbf{5}$ & 3.000 & 2.250 & $3,6-4,5$ ha & 3,6 ha & 8.100 & $9,0 \%$ \\
\hline $\mathbf{6}$ & 12.000 & 9.000 & $1,8-3,6$ ha & 2,4 ha & 21.510 & $23,9 \%$ \\
\hline $\mathbf{7}$ & 4.000 & 3.000 & $0,1-1,8$ ha & 1,1 ha & 3.150 & $3,5 \%$ \\
\hline $\mathbf{8}$ & 5.000 & 3.750 & 0 ha & 0 ha & 0 & $0,0 \%$ \\
\hline Total & 30.000 & 22.500 & ---- & ---- & 90.000 & $100,0 \%$ \\
\hline
\end{tabular}

S. 4: 0,42 T. $(=2.500 \mathrm{dr}$.)]. A partir de esto se calcula la riqueza mínima acumulada por cada sector en su conjunto [Sector 1: $300 \times 3$ T. $=900$ T.; S. $2: 900 \times 1,5$ T. $=1.350$ T.; S. $3: 1.050 \times 0,75$ T. $=787,5$ T.; S. 4: $2.250 \times 0,42 \mathrm{~T}$. $=937,5 \mathrm{~T}$. (S. 1-4: 4.500, con un riqueza mínima total de $3.975 \mathrm{~T}$.) ] y el porcentaje que cada uno aportaría a la riqueza mínima total de estos tributarios [Sector 1: $22,6 \%$; S. 2: $34,0 \%$; S. 3: $19,8 \%$; S. 4: $23,6 \%$.]. Utilizando estos porcentajes se calcula qué parte del tímema de 6.000 talentos pudo haber aportado cada uno de los sectores que tributaban la eisphorá [Sector 1: 1.356 T.; S. 2: 2.040 T.; S. 3: 1.188 T.; S. 4: 1.416 T. (tímema total del Ática: 6.000 T.)]. Para los tres sectores con tierras que no aportaban a la eisphorá $(5,6$ y 7$)$ la riqueza se calcula como un promedio entre los mínimos y los máximos que determinan el rango de la riqueza posible para cada uno [Sector 5: 2.250 x 0,38 T. (entre 2.000 y $2.500 \mathrm{dr}$.) $=844 \mathrm{~T}$.; S. $6: 9.000 \mathrm{x}$ $0,25$ T. (entre 1.000 y 2.000 dr. $)=2.250$ T.; S. $7: 3.000$ x 0,112 (entre 340 y 1.000 dr.) $=335$ T.]. Finalmente, se traduce a cantidad de hectáreas el valor monetario obtenido como riqueza promedio acumulada para cada sector, usando la ratio un pléthron $=50$ dracmas [S. 1: 14.645 ha; S. 2: 22.032 ha; S. 3: 12.830 ha; S. $4: 15.293$ ha; S. 5: 9.115 ha; S. 6: 24.300 ha; S. 7: 3.618 ha]. La sumatoria de estos parciales supera las 90.000 hectáreas de tierra privada utilizable que tomamos como referencia, por lo que procedemos a ajustar a este parámetro las cantidades obtenidas para cada sector, considerando para esto la participación porcentual de cada uno en el total que emerge de la sumatoria indicada.

${ }^{76}$ La cantidad de tierra productiva es siempre discutible; asumimos una superficie útil mayor que la destinada a cereales. FoxhaLl 1992, 156, у OBER 1985, 20, siguen a BURFORD 1977/78, 171-172. GARNSEY 1998, 183-200, 204 (cf. ID. 1988, 91-93, 102), citando bibliografía previa, calcula un área sembrada con cereales compatible con nuestra idea. Ver Sallares 1991, 79, 386; Osborne 1987, 46; ID. 2010, 92-94. La tierra productiva se reparte en $90 \%\left(900 \mathrm{~km}^{2}\right)$ de propiedad privada y $10 \%\left(100 \mathrm{~km}^{2}\right)$ de propiedad pública (FoxHALL 1992, 156). El área de cada sector se ajusta a los $900 \mathrm{~km}^{2}$ de tierra privada. Según FoxhALL 1992, 157, los ricos arrendaban la mayor parte de la tierra pública; cf. ANDREYEv 1974, 43-44; OSBORNE 1988, 291-292; pero otras posturas indican que los pobres se beneficiaban de estos arriendos: WALBANK 1983, 224-225; SHIPTON 2000, 39-49; Williams 2011, 263 y n. 11. Aquí suponemos un efecto nulo del reparto de tierra pública sobre la distribución de la tierra.

${ }^{77}$ Los miembros del sector 7 poseían pequeños lotes o huertos que los distinguían del sector 8, cuyos integrantes no tenían tierras. La riqueza de los atenienses del sector 7, que en 317 no lograron el censo de 1.000 dracmas, se estima usando datos de precios de parcelas, huertos y casas baratas reunidos por KRON 2011, 131-132. Tierras: 50 dr., $I G \mathrm{II}^{2}$ 1596, 23-24; 100 dr., $I G \mathrm{II}^{2} 1597$ (A), lín. 17-18; más de 150 dr., $I G \mathrm{II}^{2}$ 1598 A, lín. 4-5; eskhatiá: 50 dr., seis ejemplos: $I G$ II $^{2}$ 1594, lín. 27-30; 31-32; 33-34; 37-38; 39-43. Casas: khorion: 105 dr., PritchetT 1956, 270, Estela X, 16; khorion y oikídion: 300 dr., Is., 2.35; oikía, khorion y kêpos: 205 dr., Pritchett 1956, 270, Estela X, 17; oikía: 105 dr., Pritchett 1956, 270, Estela X, 15; 575 dr., Crosby - Young 1941, lín. 1-39; 215 dr., Walbank 1982, 79-82, Estela II, lín. 1-7; 145 dr., Walbank 1982, 79-82, Estela II, lín. 16-21. 
Figura 4. Gráfico de distribución de la tierra.

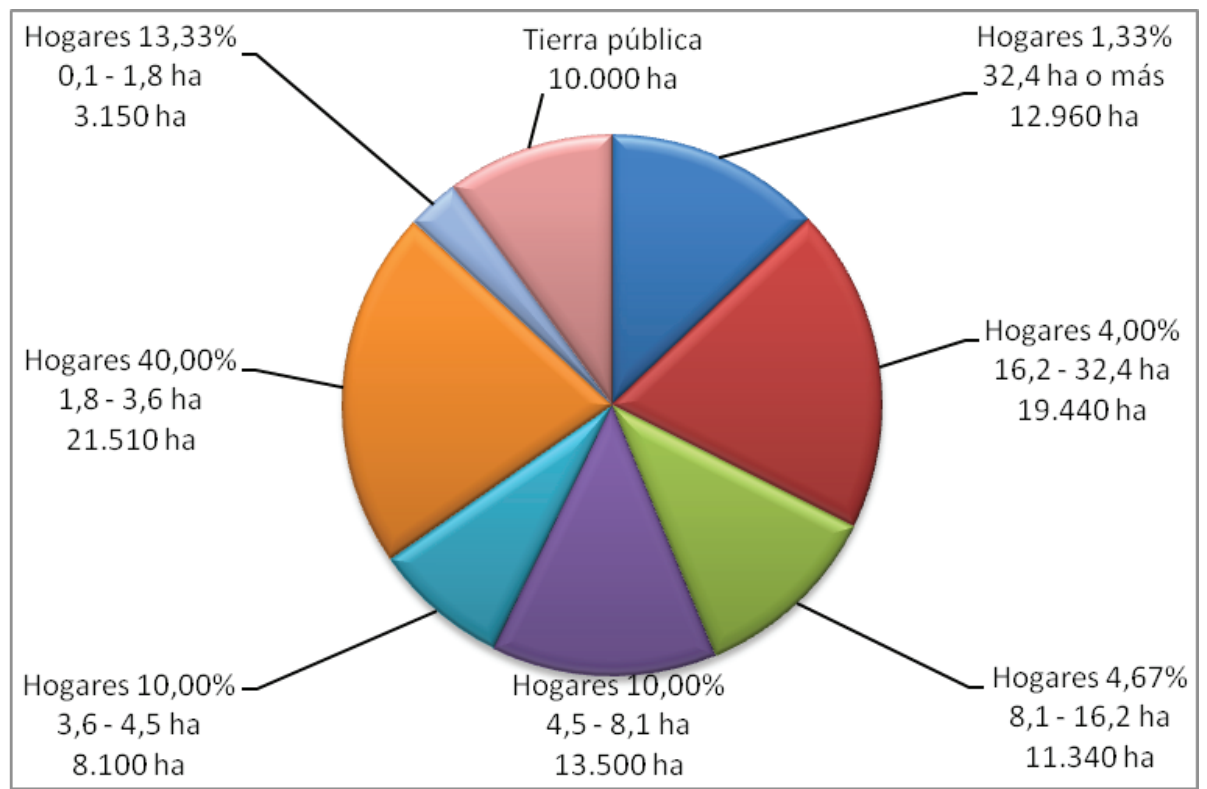

El problema estriba en cómo interpretar estos datos para ponderar el peso de cada sector. La existencia de 3.000 ciudadanos ricos integrados en 2.250 hogares (sectores 1-3) implica que el 10\% de los atenienses y los hogares poseería un 48/49\% de la tierra útil; los demás atenienses (sectores 4-7) utilizarían el 51/52\% restante. Si comparamos nuestros resultados con los de Foxhall, las principales diferencias son: en vez del 9\% de hogares en posesión del 35\% de la tierra con lotes de 10 ha o más (más $10 \%$ de tierra pública), calculamos un 10\% de hogares en posesión de casi la mitad de la tierra pero con lotes de 8 ha o más; y en vez del $68 \%$ de hogares en posesión del $55 \%$ de la tierra con lotes que promediaban 5,5 ha (pero que en la práctica rondarían las 3,6 ha), calculamos un 73\% de hogares en posesión de un poco más de la mitad de la tierra con lotes promediando 3,6 ha. Pero dejando de lado a los thêtes que pudieron tener algo de tierra (sector 7), los labradores medianos de rango hoplítico con un promedio de 50 pléthra o 4,5 ha, campesinos autónomos que en general suelen identificarse con los zeugîtai conforme a la definición de esta clase censitaria en época de Solón, formarían un grupo susceptible de integrarse dentro del conjunto más amplio de unos 18.000 atenienses que constituirían unos 13.500 hogares (sectores 4-6), esto es, el $60 \%$ de los atenienses y de los hogares que controlaría alrededor del $48 \%$ de la tierra disponible para la producción. Esta conjetura es concurrente con las visiones de Alison Burford y Michael Jameson respecto de la existencia de un modelo de agricultura familiar más extensiva, compatible con la posesión de lotes de 4 ha o más y el uso de una yunta de bueyes, y un modelo de labranza campesina más intensivo, adecuado para las unidades con 2 o 3 ha y con mayor incidencia del trabajo manual 
familiar. ${ }^{78}$ En efecto, los campesinos que poseían entre 20 y 40 pléthra (entre 1,8 y 3,6 ha) podían obtener un rendimiento que emulara al que lograban granjas familiares más grandes donde se usaba fuerza de tiro animal. Se trata de un sistema de labranza mixto basado en el policultivo y el cultivo intercalado en el que se tenía que trabajar la tierra utilizando muy intensivamente la mano de obra familiar, como ocurría en los huertos, con el consiguiente mayor gasto de energía humana. Por último, al final de la escala socioeconómica se ubicarían unos 9.000 atenienses en 6.750 hogares con escasa tierra o sin ella (sectores 7-8), el 30\% de la población y de los hogares que incluiría a buena parte de la clase tradicional de los thêtes.

En cierto sentido, nuestra estimación de la riqueza de la población campesina con respecto a la de la clase de los atenienses ricos puede parecer más desfavorable que la de Foxhall. Esto podría ser tal vez un indicio de una modificación en la distribución de la tierra acontecida entre finales del siglo $\mathrm{V}$ y el último cuarto del IV, pero también un efecto de la construcción del cuadro a partir de una segmentación de los sectores propietarios de tierras en una mayor cantidad de categorías, conforme a la información disponible y a la estabilidad demográfica asumida para el conjunto de este período. Los sectores 3 a 7 nuclearían unos 17.550 hogares, una cantidad mayor que los 15.000 que asume Foxhall. Asociar a los zeugitai más ricos con las dos primeras clases solonianas y a los poseedores de pequeños lotes con los pobres sin tierra también modifica la ecuación y las relaciones entre las clases en lo concerniente a la estructura de la propiedad agraria. Ahora bien, considerando que según nuestras estimaciones la riqueza promedio para el sector 3 , el de los zeugîtai ricos, apenas superaría las 10 ha, si restituyéramos a este sector dentro del conjunto de los labradores autónomos, siguiendo para esto la estimación de Foxhall que asumía un modo de 5,5 ha para unos 15.000 hogares con menos de 5,5 y hasta 10 ha, tendríamos entonces que los más ricos acumularían un 36\% de la tierra, mientras que un amplio grupo de casi 20.000 campesinos distribuidos en unos 15.000 hogares con entre 2 y 10 ha tendrían cerca del $60 \%$ de la tierra, que aumentaría hasta el $64 \%$ si sumáramos a los que poseían menos que 2 ha. Esto implica una ecuación más favorable para el campesinado que la de Foxhall, con una distribución de la tierra más equitativa. Pero para poder evaluar el significado de los números obtenidos debemos confrontarlos con otros cálculos con el fin de poder obtener comparativamente una perspectiva mejor definida.

\section{La riqueza del campesinado ático}

Llegados a este punto, existen diversas vías para establecer el peso relativo de la población campesina a partir de la cantidad de tierra que poseía. Lo que se observa a simple vista es que según cómo se considere al $4 / 5 \%$ de hogares procedentes de los zeugîtai ricos que poseían el $12 / 13 \%$ de la tierra del Ática, esto modifica la percepción de cuáles serían los límites de la élite y los de la clase de los campesinos autónomos. Es plausible pensar que en los inicios de la Guerra del Peloponeso los

78 Burford 1977/78, 170; EAD. 1993, 67-68; EAD. 1994, 664, 670, 672; JAMESON 1977/78, 124, 132 ; ID. 1992, 145. Cf. Halstead 1987, 83-85; Krasilnikoff 2000, 178-179. 
zeugittai ricos habían empezado a destacarse como un estrato específico por el hecho de comenzar a contribuir a la eisphorá, articulándose con las clases censitarias superiores, pentakosiomédimnoi y hippeîs. ${ }^{79}$ A partir del cobro de la eisphorá en 428, con un sistema que probablemente haya seguido funcionando hasta la reforma de 378 , la antigua clase soloniana de los zeugittai, definida de manera amplia como el conjunto de los labradores que poseían una yunta de bueyes, habría comenzado a escindirse: a fines del siglo V e inicios del IV el sector acomodado de los zeugîtai quedaría alineado junto a los atenienses ricos en función de la eisphorá. Después, una parte más amplia de este estrato, los poseedores de $4 / 5$ ha, también habría quedado incluida en la recaudación de la eisphorá, produciéndose una articulación más marcada entre las tres primeras clases solonianas, pero en momentos en que éstas ya habían perdido buena parte de su significación. Desde esta perspectiva tal vez se planteara una situación en la que el ideal del campesino-ciudadano pudo haber experimentado cierto repliegue, sin que esto hubiera estado necesariamente ligado a un empobrecimiento de los labradores ${ }^{80}$ una parte de los cuales continuaba teniendo suficiente capacidad económica para poseer una yunta de bueyes y armarse como hoplita, aun cuando esto último tendiera a perder sentido como pauta de definición del rango sociopolítico, en la medida en que durante el siglo IV la polis empezó a proveer a los atenienses el armamento requerido. ${ }^{81}$

Comparemos lo anterior con la situación en que se hallaban los campesinos áticos tras las reformas de Clístenes, considerando: 1) que éstas implicaron un cambio efectivo del estatus político de los labradores a partir del rol adquirido por los demos en el proceso democrático; 2) que a partir de la vigencia de las clases censitarias solonianas el estrato más rico de los zeugîtai, tal vez cercano económicamente al estrato inferior de los hippeîs, no obstante, quedó separado de éste por no poseer caballos, aunque sí una yunta de bueyes que lo hacía formar parte de la clase en la que había sido incluido; 3) que en virtud de esto, ciertas restricciones políticas inhibían su participación en determinadas instancias, como la imposibilidad de tener acceso al arcontado eliminada en el año 457, tras las reformas de Efialtes.

Se ha estimado que hacia 480 había entre 20.000 y 30.000 ciudadanos adultos. ${ }^{82}$ Para Jones, que asume esta última cifra, los hoplitas serían unos 10.000 , un tercio del total de la población ciudadana incluyendo la caballería; van Wees, que deduce la primera de las cantidades a partir del decreto de Temístocles, concluye que la proporción entre hoplitas y total de ciudadanos adultos sería del $40 \%$, unos 8.000 hombres. ${ }^{83}$ Es difícil deducir cuántos hoplitas provendrían de las dos clases superiores, pentakosiomédimnoi y hippeîs; pero, según los datos de períodos posteriores,

79 Argumento desarrollado en GALLEGO - VALDÉs Guía 2014, 159-162.

80 Cf. GALlEGO - VAldÉS Guía 2014, 213-238.

81 Arist., Ath., 42.4; Aeschin., 3.154; Hansen 1985, 49; ID. 1991, 109; SeKunda 1992, 345-346.

82 Para diversos cálculos de la población ateniense en los inicios del siglo V, Gomme 1933, 25-26; Patterson 1981, 48-56; Morris 1987, 99-100; Garnsey 1988, 89-91; RaAflaUb 1996, 165, n. 65; OsborNe $2010,246$.

83 Jones 1957, 8, 161; van Wees 2004, 241-243. Decreto de Temístocles: Jameson 1960. Sobre hoplitas: 9.000 en Maratón, Nep., Milt., 5.1; Paus., 10.20.2; Just., 2.9 .9 (10.000); 8.000 en Platea, Hdt., 9.28.6; Plu., Arist., 11.1. 
es pertinente pensar que no sumarían en conjunto más de 2.000 (o tal vez menos), siendo entonces entre 6.000 y 8.000 (o incluso un poco más) los hoplitas procedentes de la clase de los zeugîtai, según una u otra estimación. El formar parte de esta clase implicaba las condiciones habitualmente requeridas para ser hoplita, vigentes desde finales del arcaísmo y a comienzos de la época clásica, aunque ambos estatus no eran necesariamente correlativos. Esto supone la posesión de lotes de entre 4 y 6 ha, una yunta de bueyes y, por supuesto, el armamento hoplita. Los atenienses con lotes más pequeños o carentes de ellos ubicados por debajo de la clase de los zeugîtai formaban parte de la clase de los thêtes.

A partir de lo señalado, es factible conjeturar que a comienzos del siglo $\mathrm{V}$ la distribución de la tierra no sería muy diferente a lo indicado para el IV, aunque tal vez hubiera una cantidad mayor de zeugitai con 5 ha en promedio y un menor número de thêtes sin tierras, con cierta disminución relativa de la riqueza en manos de la élite. Esto no supone la estabilidad absoluta de todos los hogares y de las posesiones que tenían, pues entre un momento y otro se produce un gran aumento demográfico ${ }^{84} \mathrm{y}$ una merma posterior, debido a la guerra, que a inicios del siglo IV lleva los números a niveles semejantes a los de comienzos del V. Pero podría indicar que, considerada en su conjunto, la movilidad poblacional y socioeconómica entre un período y el otro habría tenido un efecto casi nulo, compensando así las pérdidas y las acumulaciones demográficas y patrimoniales de manera tal que posibilitaría la continuidad de las pautas de distribución de la tierra y, por consiguiente, de las clases sociales delimitadas conforme al acceso o no a la propiedad agraria y las proporciones del reparto patrimonial. La mayoría de los atenienses conformaría un conjunto de labradores pequeños y medianos, una parte de ellos en los umbrales de la subsistencia mientras que la otra contaría con posibilidades efectivas de cierta acumulación de riqueza, todo lo cual se puede asociar con la imagen de una Atenas sostenida en el ideal del campesino-ciudadano. Esto significa que en el siglo IV los labradores (zeugittai y thêtes con tierras) ${ }^{85}$ seguirían teniendo un lugar destacado en la sociedad ateniense, aunque tal vez con una riqueza menor respecto de sus antecesores de comienzos del siglo V.

Otra modo de cotejar nuestros cálculos es elaborando el coeficiente de Gini del reparto de la tierra. El índice de Gini y la curva de Lorenz de la cual procede permiten medir el grado de igualdad o inequidad. La curva de Lorenz (Fig. 5) representa el porcentaje acumulado de propiedades de tierra en relación con el porcentaje acumulado de hogares. El grado de máxima igualdad se establece gráficamente como una línea recta que coincide con la diagonal, surgida del cruce entre datos de hogares y de propiedades en el que cada hogar tiene la misma cantidad de tierra (el $1 \%$ posee el $1 \%$; el $10 \%$ posee $10 \%$, el $50 \%$ posee $50 \%$, etc.). El grado de desigualdad máxima aparece como un línea recta sobre el eje $(x)$ del porcentaje de hogares que al llegar al

\footnotetext{
84 No podemos desarrollar este asunto aquí (cf. Conclusión); en esta acrecentada población muchos no tendrían tierras, obteniéndolas en las cleruquías (aunque puede haber habido una mayor parcelación de la tierra ática). Las bajas bélicas y la pérdida de las colonias tras la guerra llevó a un nuevo equilibrio entre población y recursos.

85 Dejando de lado la pérdida de significación de las clases censitarias en el siglo IV; HansEN 1991, 106109.
} 
punto máximo $(100 \%)$ se eleva siguiendo el eje $(y)$ del porcentaje de tierras repartidas (un hogar posee todo y el resto nada). El índice de Gini (Figs. 6 y 7) mide el área definida entre la diagonal y la curva trazada a partir del cruce de datos de hogares y de propiedades: su valor es igual a 0 cuando la curva coincide con la diagonal (un línea recta sin área alguna), e igual a 1 cuando la curva se acopla con los ejes $x-y$ conformando un triángulo con la diagonal. Así, en la escala de $0 \mathrm{a} 1$, el primer valor muestra la igualdad absoluta y el segundo la desigualdad absoluta.

Figura 5. Curva de Lorenz de la distribución de la tierra.

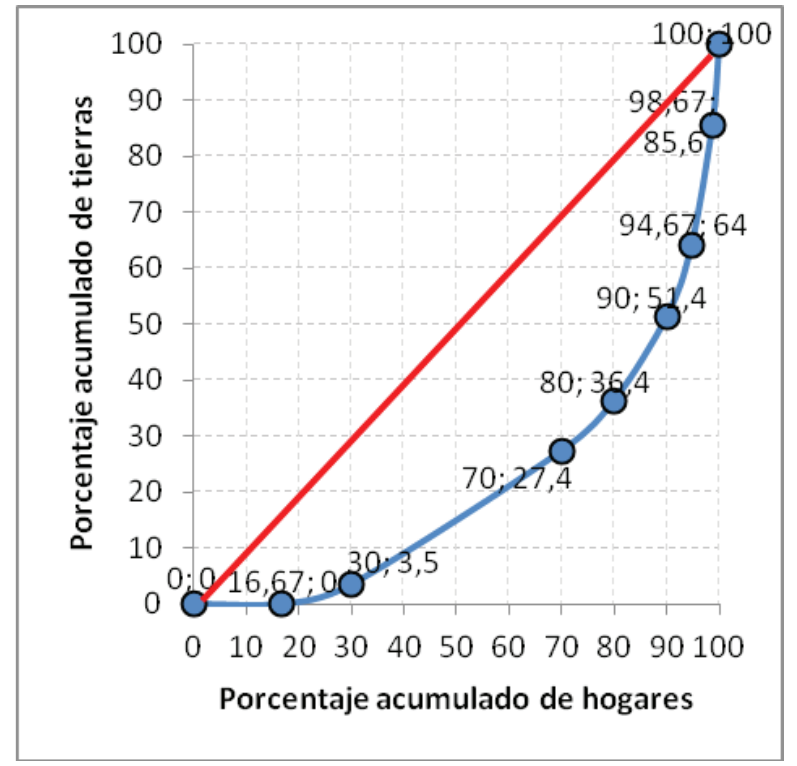

Figura 6. Coeficiente de Gini de la distribución de la tierra.

\begin{tabular}{|c|c|c|c|c|c|c|c|}
\hline Sector & $\begin{array}{c}\mathbf{x}_{\mathrm{i}} \\
\text { Lote } \\
\text { promedio } \\
\text { (hectáreas) }\end{array}$ & $\begin{array}{c}\mathbf{n}_{\mathrm{i}} \\
\text { Cantidad } \\
\text { de hogares }\end{array}$ & $\begin{array}{l}\quad \mathbf{N}_{\mathbf{i}} \\
\text { Frecuencia } \\
\text { acumulada } \\
\text { de hogares }\end{array}$ & $\begin{array}{l}\mathbf{p}_{\mathbf{i}} \\
\text { Porcentaje } \\
\text { acumulado } \\
\text { de hogares }\end{array}$ & $\begin{array}{c}\mathbf{u}_{\mathbf{i}} \\
\text { Cantidad } \\
\text { de } \\
\text { hectáreas }\end{array}$ & $\begin{array}{c}\mathbf{U}_{\mathbf{i}} \\
\text { Frecuencia } \\
\text { acumulada } \\
\text { de hectáreas }\end{array}$ & $\begin{array}{l}\qquad \mathbf{q}_{\mathbf{i}} \\
\text { Porcentaje } \\
\text { acumulado } \\
\text { de hectáreas }\end{array}$ \\
\hline 8 & 0,0 & 3.750 & 3.750 & 16,67 & 0 & 0 & 0,00 \\
\hline 7 & 1,1 & 3.000 & 6.750 & 30,00 & 3.150 & 3.150 & 3,50 \\
\hline 6 & 2,4 & 9.000 & 15.750 & 70,00 & 21.510 & 24.660 & 27,40 \\
\hline 5 & 3,6 & 2.250 & 18.000 & 80,00 & 8.100 & 32.760 & 36,40 \\
\hline 4 & 6,0 & 2.250 & 20.250 & 90,00 & 13.500 & 46.260 & 51,40 \\
\hline 3 & 10,8 & 1.050 & 21.300 & 94,67 & 11.340 & 57.600 & 64,00 \\
\hline 2 & 21,6 & 900 & 22.200 & 98,67 & 19.440 & 77.040 & 85,60 \\
\hline 1 & 43,2 & 300 & 22.500 & 100,00 & 12.960 & 90.000 & 100,00 \\
\hline \multicolumn{3}{|c|}{$p_{i}=N_{i} / N .100$} & \multicolumn{3}{|c|}{$q_{i}=U_{i} / U .100$} & \multicolumn{2}{|c|}{$I_{g}=\Sigma\left(p_{i}-q_{i}\right) / \Sigma p_{i}$} \\
\hline
\end{tabular}


Figura 7. Distribución acumulativa de la tierra entre hogares.

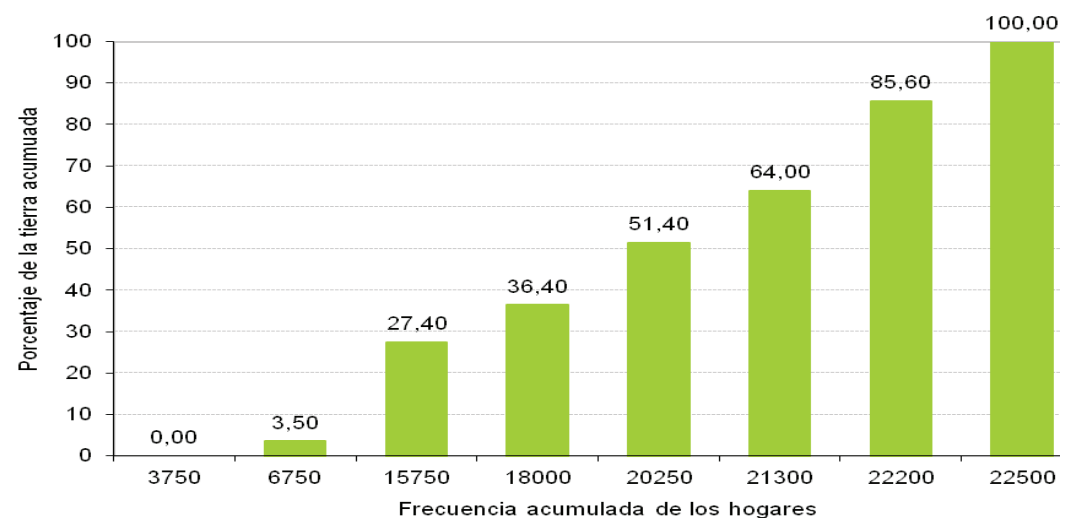

El empleo de este método para medir el grado de igualdad o desigualdad en la distribución de la tierra en el mundo antiguo fue introducido por Richard Duncan-Jones para comparar seis situaciones diferentes del Imperio romano; fue luego usado por Alan Bowman para la región del nomo Hermopolita y por Roger Bagnall también para el Egipto tardoantiguo. ${ }^{86}$ Como se observa en estos análisis, la aplicación de este método tiene un margen de error y requiere por necesidad un enfoque comparativo para poder extraer conclusiones, en nuestro caso sobre el carácter equitativo o no de la sociedad ateniense en relación con la propiedad agraria. Ian Morris ha calculado este índice a partir de las cuantificaciones de Foxhall y Osborne, llegando a un coeficiente de Gini de 0.39 (Foxhall) o 0.38 (Osborne) para el reparto de la tierra en el Ática del siglo IV. ${ }^{87}$ En nuestro caso, el coeficiente de Gini de la distribución de la tierra es de 0.441 , más elevado con respecto al cálculo de Morris debido en parte a la separación de los zeugîtai más ricos y su asociación con la élite. Pero si adecuáramos nuestra muestra a la de Foxhall repartiendo los hogares en cinco segmentos, aunque siguiendo nuestras proporciones para los diferentes sectores de la población y la cantidad de tierras de cada segmento, ${ }^{88}$ el coeficiente de Gini que obtendríamos sería de 0.36, resultando menor al calculado por Morris. Este autor lo compara con varias situaciones: las comunidades rurales del Imperio romano analizadas por Duncan-Jones, ${ }^{89}$ las del Egipto tardorromano investigadas por Bowman y Bagnall, ${ }^{90}$ la ciudad estado de Orvieto en la Italia tardomedieval, ${ }^{91} \mathrm{o}$ diversas poblaciones agrarias mediterráneas entre mediados y/o finales de los años 1940 y mediados de los

86 DunCan-Jones 1990, 121-142; Bowman 1985; BaGnall 1992.

87 Cf. Foxhall 1992; Osborne 2010, 92-94, 112-116, 127-138; Morris 2000, 140-142.

88 Foxhall 1992, 158, Fig. 1.

89 Cf. DunCAN-Jones 1990, 129-140 (entre 0.394 y 0.856). El índice para Volcei es similar al que Morris calcula para Atenas; se acercan al calculado aquí los de Ligures Baebiani y Lamasba. El resto se ubica por encima.

90 Bowman 1985, 145-155 (entre 0.616 y 0.815); Filadelfia, 0.737; Cerceosiris, 0.374; salvo este caso, el resto es más alto. BAGNALL 1992 (entre 0.431 y 0.638; para su modelo 0.500/0.560). Salvo un caso, el resto es superior.

91 Morris 2000, 141: Orvieto, 0.62 (hemos consultado la edición reciente de WALEY - DeAN 2010 ${ }^{4}, 13$ ). 
años $1960 .{ }^{92}$ De los veintidós casos cotejados solo dos arrojan índices claramente menores al que hemos calculado para Atenas (las situaciones recientes de la aldea de Orašac en Serbia y una aldea de los Sarakatsani en Grecia, población dedicada al pastoreo para la cual se consigna la propiedad de cabezas de ganado, ovejas, distribuida entre los hogares, que, en consecuencia, tal vez sea un caso menos comparable que los otros); ${ }^{93}$ otros cinco coeficientes son apenas menores o semejantes y pueden equipararse, teniendo en cuenta en cada caso los márgenes de error de las muestras realizadas (los casos para el mundo antiguo: Volcei en Lucania, Ligures Baebiani en Campania, Lamasba en Numidia y Cerceosiris y Caranis en Egipto). Así pues, de la comparación surge como resultado que la distribución de la tierra en la Atenas del siglo IV era menos desigual que la mayor parte de los ejemplos contrastados. Además, teniendo en cuenta que en el caso ateniense se toma debidamente en consideración la presencia de pobres sin tierra o con escasa propiedad, el índice obtenido para Atenas podría resultar aún más igualitario que varios de los casos comparados, puesto que no siempre se incluye a dichos segmentos de población debido a la falta de datos sobre los mismos. ${ }^{94}$

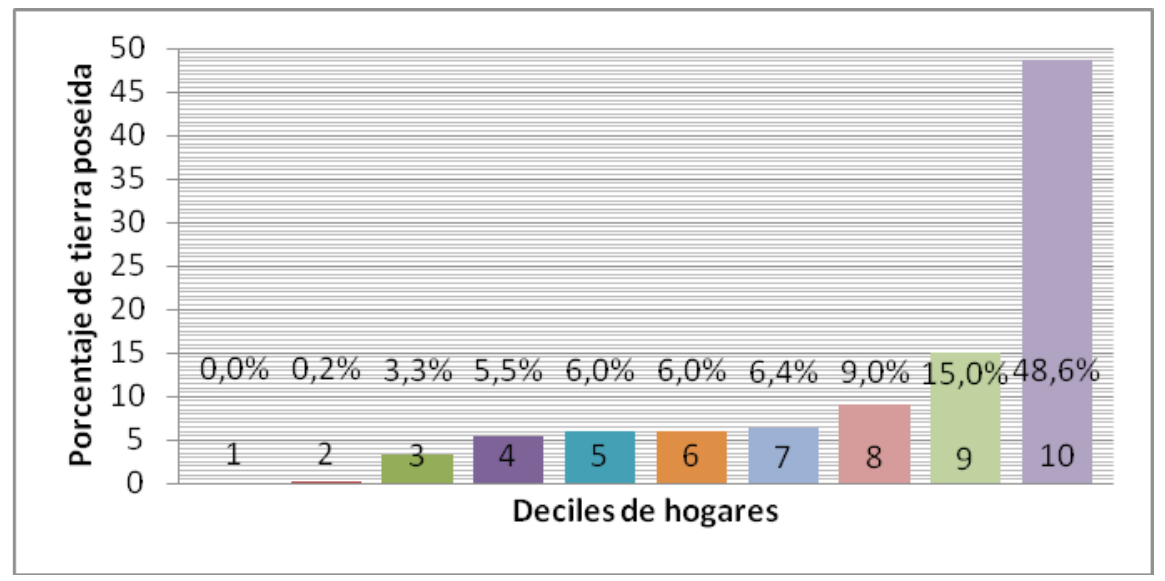

Figura 8. Distribución de la tierra por deciles de hogares.

Por su parte, Geoffrey Kron obtiene un coeficiente de Gini de 0.708 para la distribución de la riqueza, valor que compara con una muestra más ecléctica (puesto que considera varias situaciones referidas a sociedades industriales capitalistas a lo largo del siglo XX, salvo los casos de las sociedades preindustriales de Florencia y

92 Cf. Davis $2015^{2}, 88$ (entre 0.219 y 0.865). Dos casos muestran índices menores; los demás son más elevados.

93 Davis 2015², 86, Table 5, siguiendo a Campbell 1964, 357-361, Appendix I.

94 Bagnall 1992, 139: no hay datos para los grupos sin tierra; DuNCAN-Jones 1990, 121-142, también parece dejarlos afuera. WALEY - DEAN $2010^{4}, 13$, reúnen las valuaciones fiscales de la tierra poseída y afirman que dos tercios de los hogares tendrían propiedades; incluyendo entonces a un tercio sin tierras el índice es 0.69. Para las comunidades mediterráneas, DAVIS $2015^{2}, 81-89$, señala la falta de este dato o la dificultad para calcularlo. 
las ciudades toscanas a comienzos del siglo XV), ${ }^{95}$ llegando a la conclusión de que en Atenas el grado de desigualdad se sitúa entre los más bajos de la muestra. Nuestro cálculo, claro está, resulta sensiblemente menor que el coeficiente obtenido por Kron, que pondera en valores monetarios todo tipo de riqueza.

\section{Conclusión}

El examen del reparto de la tierra y de la riqueza relativa del campesinado nos ha llevado a concluir que en Atenas las pautas distributivas permanecieron aproximadamente estables y equitativas si se compara la situación de comienzos del siglo V con la del IV, aun a pesar de los significativos cambios demográficos, socioeconómicos y políticos producidos entre las Guerras Médicas y la Guerra del Peloponeso. El gran aumento de la población ciudadana en el período de la Pentecontecia no supuso una modificación de las condiciones indicadas (la mayor parte de la tierra productiva se hallaría ya asignada), pues muchos serían atenienses sin tierras viviendo de los recursos del imperio que la política de Pericles ponía a su disposición o de los lotes obtenidos en las cleruquías. La guerra contra Esparta produjo un gran declive demográfico que compensó el crecimiento previo, afectando más a los thêtes que a otros sectores y llevando la cantidad de ciudadanos a un nivel similar al que tenía a inicios del siglo V. Por ende, cuando Atenas perdió el imperio y las cleruquías (algunas de las cuales después recuperó) se vio forzada a sostenerse con sus propios recursos, sin que esto generara cambios notables en la situación rural: muchos clerucos perdieron sus lotes, pero muchos thêtes no sobrevivieron a la guerra. Esto redujo la masa de ciudadanos sin tierra, incrementada entre 480 y 430 , puesto que hacia 403 , sobre una población total que probablemente rondaría los 25.000 , unos 5.000 no poseerían tierra. La recuperación agraria y la estabilidad del campesinado a lo largo del siglo IV se asentaron sobre esta base, retornando a proporciones semejantes a las indicadas para comienzos del siglo V. Si el censo de Antípatro permite percibir la existencia de 9.000 ciudadanos con una riqueza igual o superior a la que caracterizaba al rango hoplítico, del de Demetrio se colige la presencia de un amplio sector del campesinado que, sumado a los labradores de rango hoplítico, abarcaba en total a unos 13.500 hogares y unos 18.000 varones adultos con entre 2 y 6/7 ha (como se desprende de la Fig. 8, deciles 4-9). Y aún faltaría computar a aquellos que se encontraban en el límite inferior de la clase ociosa (decil 10) con entre 8 y 10 ha, cuyo comportamiento pudo haber emulado al de los más ricos pero que en ocasiones actuaban en consonancia con las pautas de reproducción de los labradores de menor riqueza. Todas estas inferencias nos llevan a reafirmar la importancia del campesinado y a cuestionar la idea de una crisis o decadencia que lo hubiera afectado a lo largo del siglo IV, proceso que parece comenzar a verificarse recién en la época helenística. ${ }^{96}$

95 Kron 2011, 133-135 (entre 0.69 y 0.95 ).

96 Oliver 2007, 81, 108; cf. Gallant 1991, 185-196; Alcock 1993, 33-92; Hanson 1995, 388-403. 


\section{Bibliografía}

Alcock, S. E. (1993): Graecia capta. The landscapes of Roman Greece, Cambridge.

AmemiYA, T. (2007): Economy and economics of Ancient Greece (=Routledge Explorations in Economic History 33), London-New York.

AndreyeV, V. N. (1974): "Some aspects of agrarian conditions in Attica in the fifth to third Centuries B.C.", Eirene 12, 5-46.

Audring, G. (1974): "Grenzen der Konzentration von Grundeigentum in Attika während des 4. Jh. v. u. Z.”, Klio 56, 445-456.

Austin, M. M. - VidAL-Naquet, P. (1972): Économies et sociétés en Grèce ancienne (=Collection U, Histoire Ancienne 269), Paris.

BAGNALL, R. S. (1992): "Landholding in late Roman Egypt: the distribution of wealth", JRS 82, 128-149 (http://dx.doi.org/10.2307/301288).

Bayliss, A. J. (2011): After Demosthenes. The politics of early Hellenistic Athens, London.

BoEckH, A. (1842²): The public economy of Athens, London (first ed. 1828).

Bowman, A. K. (1985): "Landholding in the Hermopolite Nome in the fourth century A.D.", JRS 75, 137-163 (http://dx.doi.org/10.2307/300657).

BRESSON, A.

(2000): La cité marchande (=Scripta Antiqua 2), Bordeaux-Paris.

(2007): L'économie de la Grèce des cités. I. Les structures et la production, Paris.

BrulÉ, P. (1999): “La mortalité de guerre en Grèce classique: l'exemple d'Athènes de 490 à 322”, [en] F. Prost (ed.), Armées et sociétés de la Grèce classique, Paris, 51-68.

BRUN, P. (1983): Eisphora, syntaxis, stratiotika. Recherches sur les finances militaires d'Athènes au IV siècle av. J.-C. (= Annales Littéraires de l'Université de Besançon 284), Besançon-Paris.

Brunt, P. A. (1993): “Athenian settlements abroad in the fifth century B.C.” (or. pub. 1966), [en] Studies in Greek history and thought, Oxford, 112-136.

BurFORD, A.

(1977/78): "The family farm in ancient Greece", CJ 73, 162-175.

(1993): Land and labor in the Greek world, Baltimore.

(1994): "Greek agriculture in the classical period", [en] D. M. Lewis et alii (eds.), $C A H^{2}$, VI, 661-677.

CAmpbell, J. K. (1964): Honour, family and patronage. A study of institutions and moral values in a Greek mountain community, Oxford.

CARTledge, P. et alii (eds.), (2002): Money, labour and land. Approaches to the economies of ancient Greece, London.

CARLSEN, J. (2002): "Estate managers in ancient Greek agriculture”, [en] K. Ascani et alii (eds.), Ancient history matters. Studies presented to Jens Erik Skydsgaard (= Analecta Romana Instituti Danici Suppl. 30), Roma, 117-126.

Christ, M. R. (1990): "Liturgy avoidance and antidosis in classical Athens", TAPhA 120, 147-169 (http://dx.doi.org/10.2307/283983).

CoHen, E. E. (1992): Athenian economy and society. A banking perspective, Princeton. 
Cox, C. A. (1998): Household interests. Property, marriage strategies, and family dynamics in ancient Athens, Princeton.

Crosby, M. - Young, J. (1941): "Greek inscriptions: a poletai record of the year 367/6 B.C.", Hesperia 10, 14-30.

DAVIES, J. K. (1971): Athenian propertied families 600-300 B.C., Oxford.

(1981): Wealth and the power of wealth in classical Athens, New York.

Davis, J. (2015²): People of the Mediterranean. An essay in comparative social anthropo$\operatorname{logy}$ (=Routledge Library Editions: Social and Cultural Anthropology 5), London-New York (first ed. 1977).

DesCat, R. (1987): “L'économie d'une cité grecque au IVe s. av. J.-C.: l'exemple athénien", REA 89, 239-252.

Duncan-Jones, R. (1990): Structure and scale in the Roman economy, Cambridge.

Engen, D. T. (2010): Honor and profit. Athenian trade policy and the economy and society of Greece, 415-307 B.C., Ann Arbor.

FARAGUNA, M.

(1997). "Registrazioni catastali nel mondo greco: il caso di Atene", Athenaeum 85, 7-33. (2000). "A proposito degli archivi nel mondo greco: terra e registrazioni fondiarie", Chiron 30, 65-115.

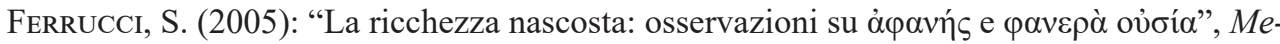
diterrAnt, 8, 145-169.

Finley, M. I. (1951): Studies in land and credit in ancient Athens, 500-200 B.C. The horosinscriptions, New Brunswick.

Finley, M. I. (ED.), (1973): Problèmes de la terre en Grèce ancienne (=Civilisations et Sociétés 33), Paris-La Haye.

FOXHALL, L.

(1992): "The control of the Attic landscape", [en] Wells (ed.), 1992, 155-159.

(1993): "Farming and fighting in ancient Greece", [en] J. Rich - G. Shipley (eds.), War and Society in the Greek World (=Leicester-Nottingham Studies in Ancient Society 4), London, 134-145.

(1997): "A view from the top: evaluating the Solonian property class", [en] L. G. Mitchell - P. J. Rhodes (eds.), The development of the polis in archaic Greece, London, 113-136. (2002): "Access to resources in classical Greece: the egalitarianism of the polis in practice", [en] Cartledge et alii (eds.), 2002, 209-220.

French, A. (1991): "Economic conditions in fourth-century Athens", $G \& R$ 38, 24-40 (http:// dx.doi.org/10.1017/S0017383500022968).

FuKs, A. (1953): The ancestral constitution. Four studies in Athenian party politics at the end of the fifth century B.C., London.

GABRIELSEN, V.

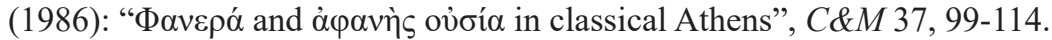

(1994): Financing the Athenian fleet. Public taxation and social relations, Baltimore.

Gallant, T. W. (1991): Risk and survival in ancient Greece. Reconstructing the rural domestic economy, Cambridge. 
GAllego, J. - VAldés Guía, M. (2014): El campesinado ático y el desarrollo de la democracia ateniense (=Estudios del Mediterráneo Antiguo/PEFSCEA 10), Buenos Aires.

GARNSEY, P.

(1988). Famine and food supply in the Graeco-Roman world. Responses to risk and crisis, Cambridge.

(1998). Cities, peasants and food in classical Antiquity. Essays in social and economic history, Cambridge.

GAuthier, P. (1966): "Les clérouques des Lesbos et la colonisation athénienne au Ve siècle", REG 79, 64-88 (http://dx.doi.org/10.3406/reg.1966.3859).

Gomme, A. W. (1933): The population of Athens in the fifth and fourth centuries B.C., Oxford.

Halstead, P. (1987): “Traditional and ancient rural economy in Mediterranean Europe: plus ça change?", JHS 107, 77-87 (http://dx.doi.org/10.2307/630071).

HANSEN, M. H.

(1985): Demography and democracy. The number of Athenian citizens in the fourth century B.C., Copenhagen.

(1988): Three studies in Athenian demography (=Historisk-filosofiske Meddelelser 56), Copenhagen.

(1991): The Athenian democracy in the age of Demosthenes. Structure, principles, and ideology, Oxford.

HANSON, V. D.

(1995): The other Greeks. The family farm and the agrarian roots of western civilization, New York.

(19982): Warfare and agriculture in classical Greece, Berkeley (first ed. 1983).

HARRIs, E. M. (2002): "Workshop, marketplace and household: the nature of technical specialization in classical Athens and its influence on economy and society", [en] Cartledge et alii (eds.), 2002, 67-99.

Hornblower, S. (1991): A commentary on Thucydides, volume I: books I-III, Oxford.

Humphreys, S. (1978): Anthropology and the Greeks, London.

JAMESON, M. H.

(1960): “A decree of Themistokles from Troizen”, Hesperia 29, 198-223.

(1977/78): "Agriculture and slavery in classical Athens", CJ 73, 122-145.

(1992): “Agricultural labor in ancient Greece”, [en] Wells (ed.), 1992, 135-146.

Jones, A. H. M. (1957): Athenian democracy, Baltimore.

Krasilnikoff, J. (2000): “On the gardens and marginal lands of classical Attica”, Proceedings of the Danish Institute at Athens 3, 177-193.

Kron, G. (2011): "The distribution of wealth at Athens in comparative perspective", ZPE 179, 129-138.

LAMBERT, S. (1997): Rationes centesimarum. Sales of public land in Lykourgan Athens (=APXAIA E $\Lambda \Lambda A \Sigma$. Monographs on Ancient Greek History and Archaeology 3), Amsterdam.

Langdon, M. K. (1985): "The territorial basis of the Attic demes", SO 60, $5-15$ (http:// dx.doi. org/10.1080/00397678508590786). 
LAPE, S. (2004): Reproducing Athens. Menander's comedy, democratic culture, and the Hellenistic city, Princeton.

Lewis, D. M. (1973): “The Athenian rationes centesimarum”, [en] Finley (ed.), 1973, 187212.

MacDowell, D. M. (1986): “The law of Periandros about symmories", CQ 36, 438-449 (http://dx.doi.org/10.1017/S0009838800012179).

MARKLE, M. M.

(1985): "Jury pay and assembly pay at Athens", [en] P. Cartledge - F. Harvey (eds.),

Crux. Essays presented to G.E.M. de Ste. Croix, Exeter, 265-297.

(1990): "Participation of farmers in Athenian juries and assemblies", AncSoc 21, 149165.

Moreno, A.

(2007): Feeding the democracy. The Athenian grain supply in the fifth and fourth centuries B.C., Oxford.

(2009): “"The Attic neighbour': the cleruchy in the Athenian empire", [en] J. Ma et alii (eds.), Interpreting the Athenian empire, London, 211-221.

MORRIS, I.

(1987): Burial and ancient society. The rise of the Greek city-state, Cambridge.

(2000): Archaeology as cultural history. Words and things in iron age Greece, Malden.

MossÉ, C.

(1962): La fin de la démocratie athénienne, Paris.

(1973): "Le statut des paysans en Attique au IVe siècle", [en] Finley (ed.), 1973, 179-186.

(1979): "Les symmories athéniennes", [en] H. van Effenterre (ed.), Points de vue sur la

fiscalité antique (=Publications de la Sorbonne: Série "Études" 14), Paris, 31-42.

NemES, Z. (1980): "The public property of demes in Attica", ACD 16, 3-8.

O'Sullivan, L. (2009): The regime of Demetrius of Phalerum in Athens, 317-307 B.C.E. A philosopher in politics (=Mnemosyme Supplement 318), Leiden.

OBER, J.

(1985): Fortress Attica. Defense of the Athenian land frontier 404-322 B.C. (=Mnemosyme Supplement 84), Leiden.

(1989): Mass and elite in democratic Athens. Rhetoric, ideology, and the power of the people, Princeton.

(2010): "Wealthy Hellas", TAPhA 140, 241-286.

Oliver, G. J. (2007): War, food and politics in early Hellenistic Athens, Oxford.

OSBORNE, R.

(1985): Demos. The discovery of classical Attika, Cambridge.

(1987): Classical landscape with figures, The ancient Greek city and its countryside, London.

(1988): "Social and economic implications of the leasing of land and property in classical and Hellenistic Greece", Chiron 18, 279-323.

(2010): Athens and Athenian democracy, Cambridge.

PAPAZARKADAS, N. (2011): Sacred and public land in ancient Athens, Oxford.

Patterson, C. (1981): Pericles' citizenship law of 451-50 B.C., New York.

PeČIRKA, J. (1976): “The crisis of the Athenian polis in the fourth century B.C.”, Eirene 13, 5-29. 
Poddighe, E. (2002): Nel segno di Antipatro. L'eclissi della democrazia ateniese dal 323/2 al 319/8 a.C., Roma.

Pritchett, W. K. (1956): “The Attic stelai: part II”, Hesperia 25, 178-317.

RAAFLAUb, K. A. (1996): "Equalities and inequalities in Athenian democracy”, [en] J. Ober - C. Hedrick (eds.), Demokratia. A conversation on democracies, ancient and modern, Princeton, 139-174.

REED, C. M. (2003): Maritime traders in the ancient Greek world, Cambridge.

RHOdes, P. J. (1982): "Problems in Athenian eisphora and liturgies", AJAH 7, 1-19.

Rosivach, V. J.

(1993): "The distribution of population in Attica", GRBS 34, 391-407.

(2000): "Some economic aspects of the fourth-century Athenian market in grain", Chiron 30, 31-64.

RuSCHENBUSCH, E.

(1978): “Die athenischen Symmorien des 4. Jh. v. Chr.", ZPE 31, 275-284.

(1985): "Die Sozialstruktur der Bürgerschaft Athens im 4. Jh. v. Chr.", ZPE 59, 249-251.

(1987): "Symmorienprobleme", ZPE 69, 75-81.

SALlaRes, R. (1991): The ecology of the ancient Greek world, London.

SEKUNDA, N. V. (1992): "Athenian demography and military strength 338-322 B.C.", ABSA 87, 311-355 (http://dx.doi.org/10.1017/S0068245400015203).

ShIPton, K. (2000): Leasing and lending. The cash economy in fourth-century B.C. Athens (=Bulletin of the Institute of Classical Studies Supplement 74), London.

Ste. CRoIX, G. DE

(1953): "Demosthenes $\tau i ́ \mu \eta \mu \alpha$ and the Athenian eisphora in the fourth century B.C.", C\&M 14, 30-70.

(1966): "The estate of Phainippos (Ps.-Dem., XLII)", [en] E. Badian (ed.), Ancient society and institutions. Studies presented to Victor Ehrenberg, Oxford, 109-114.

(1981): The class struggle in the ancient Greek world, London.

Strauss, B. S. (1986): Athens after the Peloponnesian War. Class, faction and policy, 403386 B.C., Ithaca.

Stroud, R. S. (1998): The Athenian grain-tax law of 374/3 B.C. (=Hesperia Supplement 29), Princeton (http://dx.doi.org/10.2307/1354031).

Thompson, W. E. (1971): “The deme in Kleisthenes' reform”, SO 46, $72-79$ (http://dx.doi. org/10.1080/00397677108590627).

Thomsen, R. (1964): Eisphora. A study of direct taxation in ancient Athens (=Humanitas 3), Copenhagen.

Thorne, J. A. (2001): "Warfare and agriculture: the economic impact of devastation in classical Greece", GRBS 42, 225-253.

VALDÉs GứA, M.

(2014): "Patrimonio de Demóstenes como hegemón de su 'sinmoría': eisphorá y proeisphorá tras el 378", Emerita 82, 249-271 (http://dx.doi.org/10.3989/emerita.2014.03.1234). (2015): "La renovación de la dependencia en el siglo IV: los espacios de thetes y misthotoi", [en] A. Beltrán et alii (eds.), Los espacios de la esclavitud y la dependencia desde la Antigüedad, Besançon, 183-199. 
VAN WEES, H.

(2001): "The myth of the middle-class army: military and social status in ancient Athens", [en] T. Bekker-Nielsen - L. Hannestad (eds.), War as a cultural and social force. Essays on warfare in Antiquity (=Historisk-filosofiske Skrifter 22), Copenhagen, 4571. (2004): Greek warfare. Myths and realities, London. (2006): "Mass and elite in Solon's Athens: the property classes revisited", [en] J. Blok A. Lardinois (eds.), Solon of Athens. New historical and philological approaches (=Mnemosyne Supplement 272), Leiden, 351-389.

(2011): "Demetrius and Draco. Athens' property classes and population in and before 317 B.C.”, JHS 131, 95-114 (http://dx.doi.org/10.1017/S0075426911000073).

WALBANK, M. B.

(1982): "The confiscation and sale by the poletai in 403/2 B.C. of the property of the Thirty tyrants", Hesperia 51, 74-98.

(1983): "Leases of sacred properties in Attica, parts I-IV", Hesperia 52, 100-135, 177 199, 200-206, 207-231.

(1984): "Leases of sacred properties in Attica, part V", Hesperia 53, 361-368.

Waley, D. P. - Dean, T. (20104): The Italian city republics, London-New York (first ed. 1969).

Wallace, R. W. (1989): “The Athenian proeispherontes", Hesperia 58, 473-490.

Wells, B. (ED.), (1992): Agriculture in ancient Greece (=Acta Instituti Atheniensis Regni Sueciae 42), Stockholm.

WiLliams, A. (2011): "Leasing of sacred land in 4th-century Athens: a reassessment of six inscribed fragments", Hesperia 80, 261-286 (http://dx.doi.org/10.2972/hesperia.80.2.0261).

Williams, J. M. (1983): “Solon's class system, the manning of Athens' fleet, and the number of Athenian thetes in the late fourth century", ZPE 52, 241-245.

Wood, E. M. (1983). “Agricultural slavery in classical Athens”, AJAH 8, 1-47. 